\title{
ARTICLE
}

\section{ATP-dependent substrate transport by the ABC transporter MsbA is proton-coupled}

Himansha Singh ${ }^{1}$, Saroj Velamakanni ${ }^{1}$, Michael J. Deery ${ }^{2}$, Julie Howard ${ }^{2}$, Shen L. Wei ${ }^{1} \&$ Hendrik W. van Veen ${ }^{1}$

ATP-binding cassette transporters mediate the transbilayer movement of a vast number of substrates in or out of cells in organisms ranging from bacteria to humans. Current alternating access models for $A B C$ exporters including the multidrug and Lipid $A$ transporter MsbA from Escherichia coli suggest a role for nucleotide as the fundamental source of free energy. These models involve cycling between conformations with inward- and outwardfacing substrate-binding sites in response to engagement and hydrolysis of ATP at the nucleotide-binding domains. Here we report that MsbA also utilizes another major energy currency in the cell by coupling substrate transport to a transmembrane electrochemical proton gradient. The dependence of ATP-dependent transport on proton coupling, and the stimulation of MsbA-ATPase by the chemical proton gradient highlight the functional integration of both forms of metabolic energy. These findings introduce ion coupling as a new parameter in the mechanism of this homodimeric $A B C$ transporter.

\footnotetext{
${ }^{1}$ Department of Pharmacology, University of Cambridge, Tennis Court Road, Cambridge CB2 1PD, UK. ${ }^{2}$ Department of Biochemistry, Cambridge Centre for Proteomics, University of Cambridge, Tennis Court Road, Cambridge CB2 1GA, UK. Correspondence and requests for materials should be addressed to H.W.v.V. (email: hwv20@cam.ac.uk).
} 
A TP-binding cassette $(\mathrm{ABC})$ multidrug exporters are embedded in the plasma membrane and actively extrude cytotoxic drugs from the cell ${ }^{1}$. They play a critical role in the failure of pharmacological treatment of microbial diseases and cancers, affect drug pharmacokinetics in mammals and are a prime target for clinical research ${ }^{2,3}$. Some of these transporters, including the mammalian multidrug resistance $\mathrm{P}$-glycoprotein $\mathrm{ABCB} 1$ and its bacterial homologues MsbA and LmrA, transport lipids and chemotherapeutic drugs from the inner leaflet of the plasma membrane to the outer leaflet and extracellular environment ${ }^{4-8}$.

$\mathrm{ABC}$ exporters are thought to utilize the free energy from ATP-binding and hydrolysis at two nucleotide-binding domains (NBDs) to transport substrates via a translocation pathway that is formed by two membrane domains (MDs $)^{9,10}$. In ABCB1, these four domains are fused on a single polypeptide, whereas in bacterial MsbA and LmrA, an MD is fused to an NBD in a half-transporter that homodimerizes to form the full transporter. Current structural and biochemical data support an 'alternating access' model in which the substrate-binding sites in the MDs are exposed to either side of the membrane as the transporter alternates between inward-facing and outwardfacing conformational states ${ }^{11-13}$. The transition from the inward-facing conformation to the outward-facing conformation is governed by ATP-binding-associated NBD dimerization, often referred to as 'the power stroke', after which ATP hydrolysis and ADP-and-Pi-release-dependent NBD dissociation resets the transporter to the inward-facing conformation. However, many important details of this mechanism remain to be elucidated. MsbA transports cytotoxic agents and the Lipid A anchor of lipopolysaccharides ${ }^{14-17}$, and is an essential transporter in many Gram-negative bacteria ${ }^{18-20}$. Here we show for Escherichia coli MsbA that ATP binding and hydrolysis are insufficient to drive drug transport in the absence of an electrochemical proton gradient. We conclude that proton coupling is essential in the nucleotide-dependent power stroke in MsbA.

\section{Results}

Studies in intact cells. Energy coupling by MsbA was first studied in ATP-depleted Lactococcus lactis cells with a very low internal ATP concentration of $\sim 7 \mu \mathrm{M}$ (ref. 21 ) that were preloaded with $2 \mu \mathrm{M}$ ethidium by reversed transport by $\mathrm{MsbA}^{15,16}$ (Fig. 1). After a steady state was reached, the addition of glucose raised the intracellular ATP concentration to $\sim 9 \mathrm{mM}$ (ref. 21 ), and initiated a significant ethidium efflux activity by wild-type MsbA (MsbA-WT) compared with the non-expressing control (Fig. 1c,d). Surprisingly, ethidium efflux was also observed for cells containing MsbA-MD (Fig. 1c,d), a truncated form of MsbA-WT that lacks the NBD and that is expressed in a similar orientation and at a moderately elevated level (117\%) in the plasma membrane compared with MsbA-WT (Fig. 1a,b). To investigate the possibility that transport by MsbA-MD in these cells is dependent on an electrochemical proton gradient, also referred to as the protonmotive force $(\Delta p$, interior positive and acidic), or one of its components, the transmembrane $\mathrm{pH}$ gradient $(\Delta \mathrm{pH})$ and electrical membrane potential difference $(\Delta \psi)$, measurements of ethidium efflux by MsbA-MD were repeated in cells in which the magnitude and composition of the $\Delta p(=\Delta \psi-Z \Delta \mathrm{pH}$ in which $Z$ is approximately equal to $58 \mathrm{mV}$ at $20^{\circ} \mathrm{C}$ ) was manipulated with the ionophores nigericin and valinomycin ${ }^{22}$. The results show that ethidium efflux by MsbA-MD was completely inhibited in the presence of the $\Delta \psi$ only. In contrast, significant efflux was observed in the presence of the $\Delta \mathrm{pH}$ only (Fig. 1e). The results for MsbA-WT (Fig. 1f) showed similarities with those for MsbA-MD, and both were clearly different from non-expressing control cells for which no ethidium efflux was observed (Fig. 1g). Previous studies in cells highlighted the dependency of ethidium efflux by MsbA-WT on ATP binding and hydrolysis; the efflux activity is strongly inhibited by impairment of the MsbA-ATPase activity down to $4-6 \%$ of WT activity through the deletion of the Walker A lysine residue at position $382(\Delta \mathrm{K} 382 \text { mutation })^{16,23}$. Indeed, although the expression level of MsbA- $\Delta \mathrm{K} 382$ was only slightly below that of MsbA-WT (77\%; Fig. 1a), the ethidium transport activity of the mutant was strongly inhibited (Fig. 1c,d). Taken together, these findings suggest that MsbA-mediated ethidium efflux is dependent on both the electrochemical proton gradient and ATP hydrolysis.

Proton-coupled substrate transport in proteoliposomes. To investigate the dependence of transport activity of MsbA on the electrochemical proton gradient in the absence of nucleotides and other components, MsbA-WT, MsbA-MD, MsbA- $\Delta \mathrm{K} 382$ and the transport-inactive triple mutant MsbA-DED (D41N in transmembrane helix (TMH) 1, E149Q in TMH 3 and D252N in $\mathrm{TMH}$ 5) were affinity-purified and reconstituted in proteoliposomes prepared from E. coli phospholipids ${ }^{7,24}$. Unlike whole cells, spheroplasts and plasma membrane vesicles, these proteoliposomes are devoid of cytoplasmic constituents and alternative primary-active and secondary-active transporters, allowing studies on the transport and energetics of purified MsbA proteins in the absence of energy-transducing transport processes. The MsbA proteins incorporated equally well in proteoliposomes and were present in an inside-out orientation (Fig. 2a,b). Purified MsbA-WT and MsbA-MD samples used for the reconstitution experiments were examined by LC-MS/MS mass spectrometry. This analysis confirmed the lack of the native NBD in the MsbA-MD protein (Fig. 2c). The Mascot database was also searched against the UniProt L. lactis subsp. lactis database, which demonstrated insignificant levels of contaminating membrane transporters and ABC NBDs (Supplementary Data 1 ), below $0.01 \%$ for MsbA-WT and $0.7 \%$ for MsbA-MD when the exponentially modified protein abundance index was used as a measure for the protein abundance ${ }^{25}$.

To study the functionality of the MsbA proteins in the proteoliposomes, a $\Delta \mathrm{pH}$ (interior acidic) was generated by $\mathrm{pH}$ jump (Fig. 3). In this method, proteoliposomes prepared in buffer $\mathrm{pH} 6.8$ were diluted in buffer $\mathrm{pH}$ 8.0, imposing a difference between the interior $\mathrm{pH}$ and external $\mathrm{pH}$ by $\mathrm{pH}$ jump $\left(\mathrm{pH}_{\mathrm{in}}\right.$ $6.8 / \mathrm{pH}_{\text {out }} 8.0$ ). This $\mathrm{pH}$ difference was sustained by dissociation of $\mathrm{NH}_{4}^{+}$in the lumen of proteoliposomes and the outward diffusion of $\mathrm{NH}_{3}$. The $\Delta \psi$ (interior positive) was imposed by diffusion of $\mathrm{SCN}^{-}$from the lumen down an outwardly directed chemical gradient $\left(\left[\mathrm{SCN}^{-}\right]_{\text {in }} /\left[\mathrm{SCN}^{-}\right]_{\text {out }}=100 \mathrm{mM}\right.$ versus $1 \mathrm{mM})$. No changes in ethidium fluorescence were observed upon imposition of $\Delta \psi$ and/or $\Delta \mathrm{pH}$ in liposomes lacking MsbA proteins (Fig. 4a) or containing inactive MsbA-DED (Fig. 4b). These results are consistent with the mass spectrometry data showing the absence of contaminating membrane transporters in our protein preparations (Fig. 2c and Supplementary Data 1). However, for both MsbA-WT (Fig. 4c) and MsbA-MD (Fig. 4d), ethidium transport in the proteoliposomes with the imposed $\Delta \mathrm{pH}$ (interior acidic) was significantly higher, more than fivefold for MsbA-WT compared with the equilibration level in the no-gradient controls $\left(\mathrm{pH}_{\mathrm{in}} 6.8 / \mathrm{pH}_{\text {out }} 6.8\right.$ and $\mathrm{pH}_{\text {in }} 8.0 / \mathrm{pH}_{\text {out }} 8.0$ ). These results point to concentrative $\Delta \mathrm{pH}$-dependent accumulation of ethidium. In contrast, uptake of ethidium by MsbA-WT and MsbA-MD was not stimulated in the presence of a reversed $\Delta \mathrm{pH}$ $\left(\Delta \mathrm{pH}_{\mathrm{REV}}\right.$, interior alkaline), which was imposed by the passive diffusion of acetic acid from the lumen of the proteoliposomes 
a

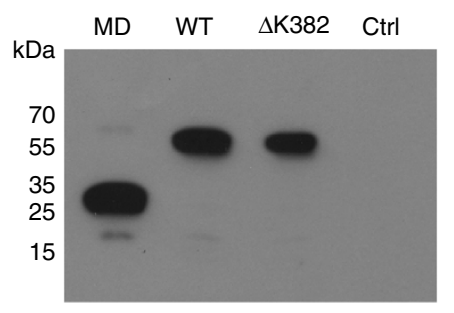

b
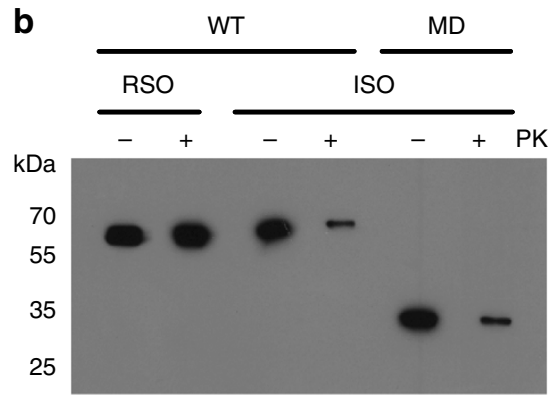

C

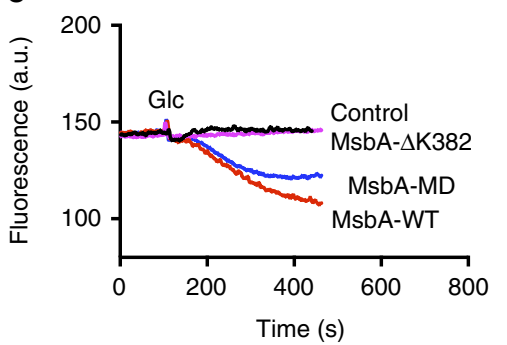

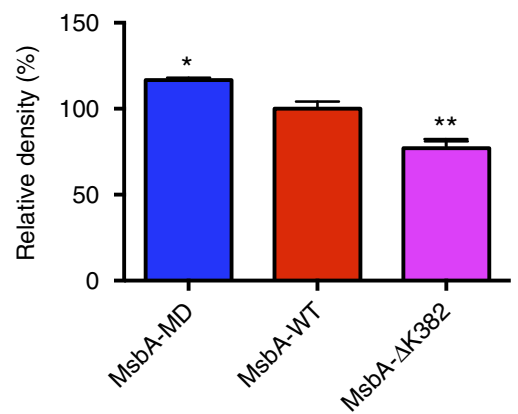

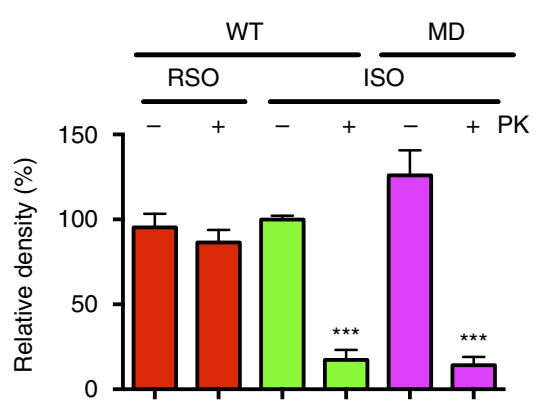

d

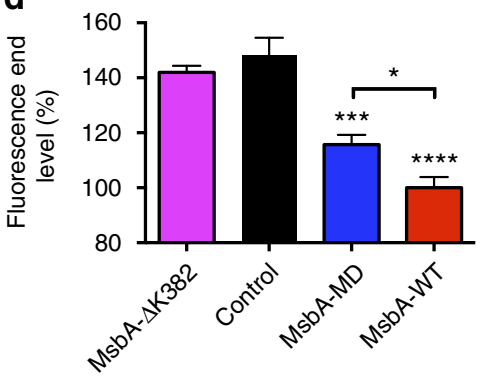

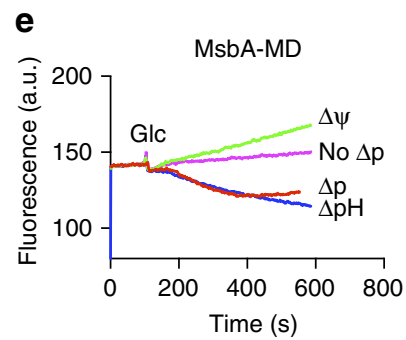
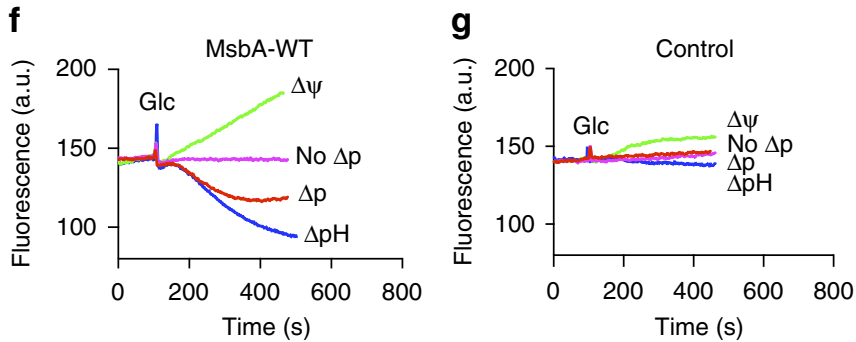

Figure 1 | Ethidium efflux in intact cells. (a) Immunoblot probed with anti-polyhistidine tag antibody (left) shows that MsbA-MD and MsbA- $\Delta K 382$ are expressed in the plasma membrane of L. lactis ( $5 \mu \mathrm{g}$ total membrane protein per lane) at $117 \%$ and $77 \%$ of MsbA-WT, respectively, and that these proteins are absent in control cells (Ctrl). The migration of molecular mass markers is indicated. Histogram (right) shows MsbA signal intensities. (b) Availability of the cytosolic $\mathrm{NH}_{2}$-terminal His-tag in MsbA-WT and MsbA-MD to cleavage by proteinase $\mathrm{K}(+\mathrm{PK})$ at the external side of right-side-out (RSO) or inside-out (ISO) membrane vesicles (3 $\mu$ g protein per lane). Incubation without the protease (-PK) served as control. Uncleaved His-tag was detected on immunoblot (left). Signal intensities are shown in the histogram (right). (c) Efflux of monovalent cationic ethidium was initiated by the addition of 20 mm glucose $(\mathrm{Glc})$ as a source of metabolic energy to ATP-depleted cells that were preloaded with $2 \mu \mathrm{M}$ of the dye. Efflux was observed for MsbA-WT but not for non-expressing control or MsbA- $\Delta \mathrm{K} 382$, which exhibits a strongly reduced ATPase activity due to the absence of the catalytic Walker $\mathrm{A}$ lysine residue. Remarkably, ethidium efflux was also observed for a truncated form of MsbA-WT that lacks the NBD (MsbA-MD). (d) Histogram shows significance of fluorescence levels in (c) at $t=400 \mathrm{~s}$. (e-g) Ethidium efflux from cells containing MsbA-MD (e), MsbA-WT (f) or no MsbA proteins ( $\mathrm{g}$ ) to which ionophores nigericin ( $\Delta \psi$ only, interior negative), valinomycin ( $\Delta \mathrm{pH}$ only, interior alkaline) or both (no $\Delta p$ ) were added at concentrations of 1.0 and $0.1 \mu \mathrm{M}$, respectively, $3 \mathrm{~min}$ prior to the addition of the glucose. Data represent observations in 3 or more independent experiments with independently prepared batches of cells. Values in histograms are expressed as mean \pm s.e.m. (one-way analysis of variance; ${ }^{\star} P<0.05 ;{ }^{\star \star} P<0.01 ;{ }^{\star \star \star} P<0.001 ;{ }^{\star \star \star \star} P<0.0001$ ).

(Figs 3 and $4 \mathrm{c}, \mathrm{d})$. Upon the imposition of the $\Delta \psi$ plus $\Delta \mathrm{pH}$ $(\Delta p$, interior positive and acidic), ethidium transport was above control but was reduced compared with the activity obtained in the presence of the $\Delta \mathrm{pH}$ only (Fig. 4c,d). As these results suggested that the imposed $\Delta \psi$ (interior positive) was inhibitory for ethidium transport in proteoliposomes, the effect of reversed $\Delta \psi\left(\Delta \psi_{\mathrm{REV}}\right.$, inside negative $)$ was tested. The $\Delta \psi_{\mathrm{REV}}$ was imposed in the proteoliposomes by the electrogenic downhill diffusion of $\mathrm{K}^{+}$from the lumen to the external buffer by valinomycin (added at $10 \mathrm{nmol}(\mathrm{mg} \text { of protein })^{-1}$; Fig. 3), and was found 

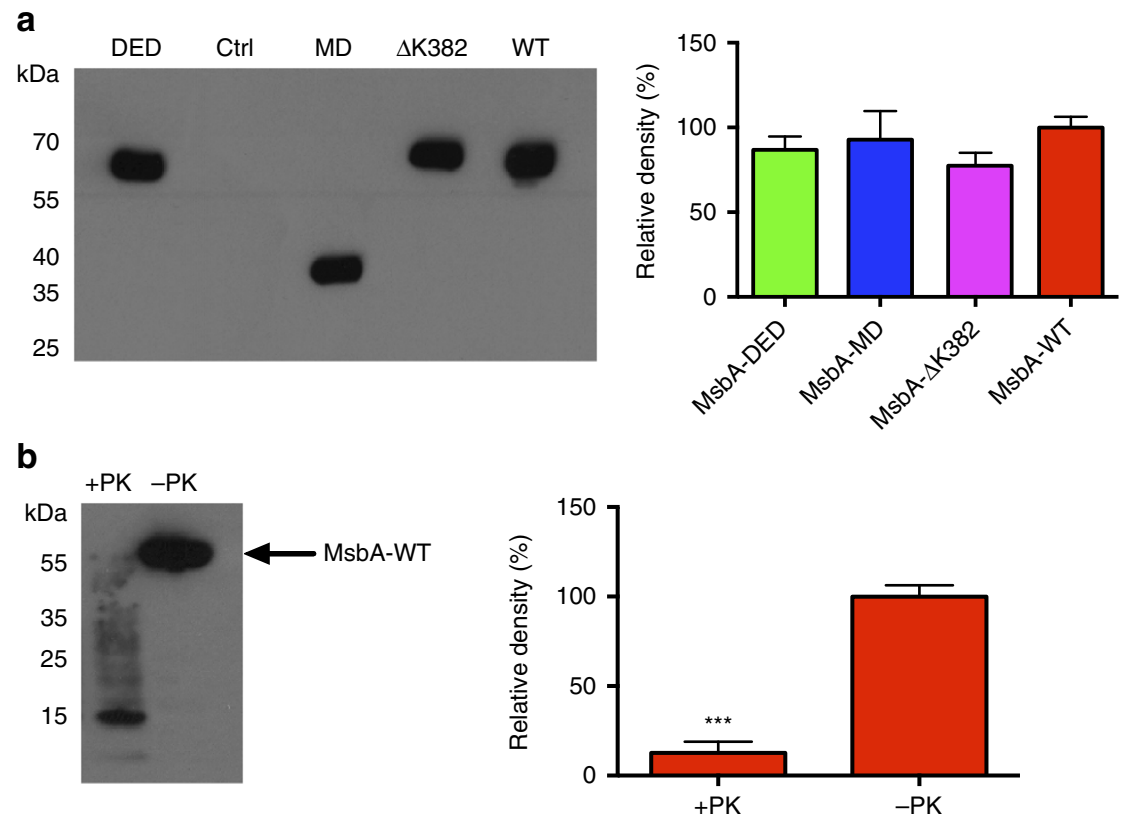

C

MsbA-WT

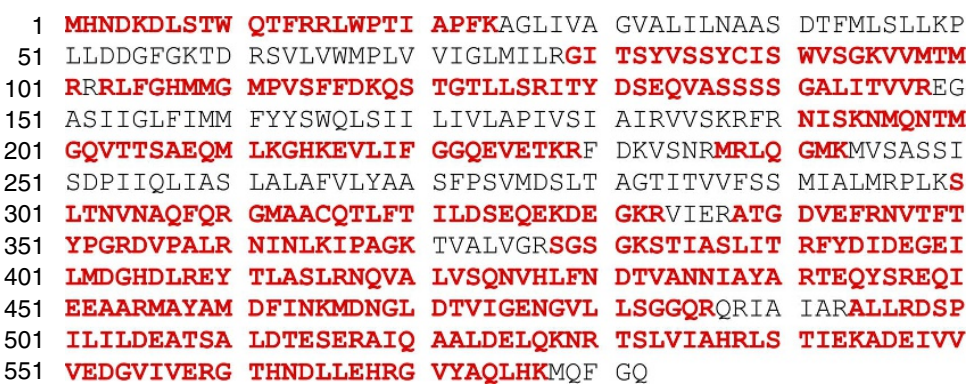

MsbA-MD

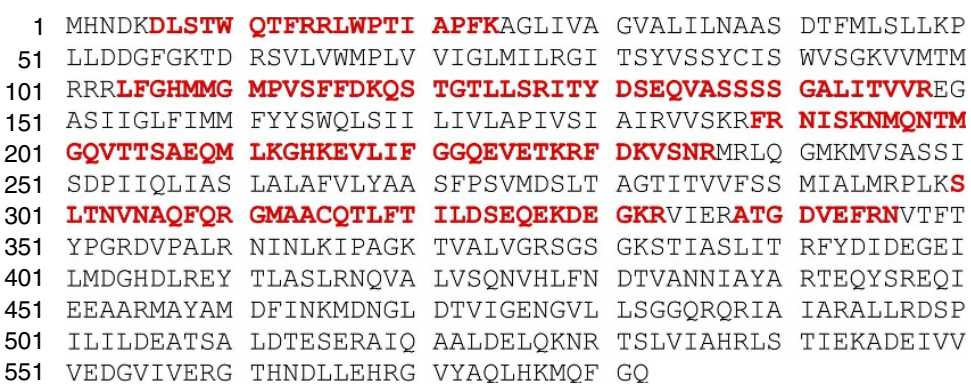

Figure 2 | Purified MsbA proteins in proteoliposomes. (a) Immunoblot of proteoliposomes prepared from $E$. coli phospholipids (5 $\mu$ g protein per lane) (left) demonstrates the equal incorporation of purified transport-inactive triple mutant MsbA-DED, MsbA-MD, MsbA- $\triangle K 382$ and MsbA-WT, and the absence of membrane proteins in empty control liposomes (Ctrl). Histogram (right) shows MsbA signal intensities. (b) Availability of the His-tag in MsbA-WT ( $3 \mu \mathrm{g}$ protein per lane) to cleavage by Proteinase K (PK) at the external side of proteoliposomes (left) and corresponding signal intensities (right) demonstrate the inside-out orientation of the reconstituted protein. (c) Purified MsbA-WT and MsbA-MD preparations for reconstitution experiments were subjected to LC-MS/MS mass spectrometry. Mascot protein coverage maps for MsbA-WT and MsbA-MD are shown. The sequence stretches in red correlate to the peptides that were identified in these experiments. The MsbA-MD sequence shows a lack of peptides identified along the NBD stretch of full-length MsbA-WT. Data represent observations in three or more independent experiments with independently prepared batches of proteoliposomes. Values in histograms are expressed as mean \pm s.e.m. (a, one-way analysis of variance; $b$, unpaired student- $t$ test; ${ }^{\star \star \star} P<0.001$ ).

to stimulate ethidium transport in the proteoliposomes, also when combined with the $\Delta \mathrm{pH}$ (interior acidic), yielding $\Delta p_{\Delta \psi \mathrm{REV}}=\Delta \psi_{\mathrm{REV}}-Z \Delta \mathrm{pH}$ (Fig. 4e). No increase in ethidium fluorescence was observed under these conditions in liposomes lacking MsbA proteins (Fig. 4f). When taken together in the physiological context of the cell $(\Delta p$, interior negative and alkaline), these findings indicate that the $\Delta \mathrm{pH}$ (interior alkaline) supports ethidium efflux by MsbA-WT and MsbA-MD, whereas the $\Delta \psi$ (interior negative) inhibits this activity.

Proton-coupled substrate transport by MsbA proteins was also observed for the neutral antibiotic chloramphenicol ${ }^{20}$. The 100-fold dilution of (proteo)liposomes in dilution buffer 


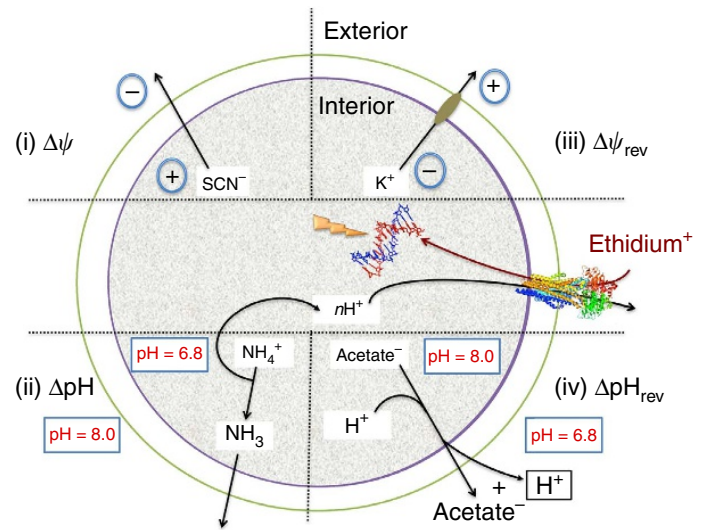

Figure 3 | Schematic showing methods for artificial imposition of electrochemical ion gradients in proteoliposomes. The $\Delta \psi$ (interior positive), $\Delta \mathrm{pH}$ (interior acidic), $\Delta p$ (interior positive and acidic), $\Delta \psi_{\mathrm{REV}}$ (interior negative), $\Delta p_{\Delta \psi \mathrm{REV}}$ (interior negative and acidic), or $\Delta \mathrm{pH} \mathrm{H}_{\mathrm{REV}}$ (interior alkaline) were imposed by 100 -fold dilution of proteoliposomes containing inside-out oriented MsbA-WT or MsbA-MD as described in the main text. Inclusion of DNA in the lumen allows the recording of the fluorescence emission of accumulated ethidium.

containing $2 \mu \mathrm{M} \quad\left[{ }^{3} \mathrm{H}\right]$-chloramphenicol initiated the timedependent accumulation of chloramphenicol in proteoliposomes containing reconstituted MsbA-WT or MsbA-MD in the presence of the imposed $\Delta \mathrm{pH}$ (interior acidic), but not in the absence of the $\Delta \mathrm{pH}$ or in empty liposomes without MsbA proteins (Fig. 5a,b). Thus, the proton dependence of MsbA-mediated transport is observed for two different substrates, chloramphenicol and ethidium, with different charge and hydrophobicity. Using (proteo)liposomes loaded with the $\mathrm{pH}$ indicator 2',7'-bis-(2-carboxyethyl)-5-(and-6)-carboxyfluorescein (BCECF), the fluorescence emission of which increases at alkaline $\mathrm{pH}$, chloramphenicol uptake by MsbA-WT in the proteoliposomes was found to be associated with proton efflux down its chemical gradient $\left(\mathrm{pH}_{\text {in }} 6.8 / \mathrm{pH}_{\text {out }} 8.0\right.$; Fig. $\left.5 \mathrm{c}\right)$. This result is consistent with the no-gradient control experiments in Fig. 4c in which ethidium transport by MsbA-WT in proteoliposomes was not initiated by changes in local $\mathrm{pH}$ in the lumen or external buffer $\left(\mathrm{pH}_{\text {in }} 6.8 / \mathrm{pH}_{\text {out }} 6.8\right.$ and $\mathrm{pH}_{\text {in }} 8.0 / \mathrm{pH}_{\text {out }}$ 8.0) but required the imposition of a transmembrane $\Delta \mathrm{pH}$ (interior acidic).

Proton coupling is functionally linked to ATP hydrolysis. In view of the finding that ethidium transport by MsbA is dependent on ATP hydrolysis (Fig. 1c) and components of the $\Delta p$ (Figs if and $4 c, e)$, the relationship between these two forms of metabolic energy was further studied in proteoliposomes. For this purpose, ethidium uptake in MsbA-WT-containing proteoliposomes was measured in the absence or presence of the imposed $\Delta \mathrm{pH}$ (inside acidic; $\mathrm{pH}_{\text {in }} 6.8 / \mathrm{pH}_{\text {out }} 8.0$ ) in buffer containing $2.5 \mathrm{mM}$ Mg-ATP or non-hydrolysable nucleotide analogue AMP-PNP. Remarkably, the ATP did not initiate ethidium accumulation in the absence of the $\Delta \mathrm{pH}$, nor did the nucleotide enhance $\Delta \mathrm{pH}$-dependent transport (Fig. 6a). However, the $\Delta \mathrm{pH}$ dependent accumulation of ethidium was strongly inhibited by the replacement of ATP by the non-hydrolysable analogue AMP-PNP (Fig. 6a). These data demonstrate the importance of ATP hydrolysis by MsbA-WT in experiments where ATP is co-applied with the imposed $\Delta \mathrm{pH}$. In agreement with this, measurements of the MsbA-ATPase activity in proteoliposomes showed that imposition of the $\Delta \mathrm{pH}\left(\mathrm{pH}_{\mathrm{in}} 6.8 / \mathrm{pH}_{\text {out }} 8.0\right)$ stimulated the ATPase activity of MsbA-WT compared with controls in which the $\Delta \mathrm{pH}$ was dissipated through the addition of nigericin $\left(\mathrm{pH}_{\text {in }}\right.$ becomes equal to $\mathrm{pH}_{\text {out }}=8.0$; Fig. $\left.6 \mathrm{~b}, \mathrm{c}\right)$ or in which the $\Delta \mathrm{pH}$ was not imposed $\left(\mathrm{pH}_{\mathrm{in}} / \mathrm{pH}_{\text {out }}\right.$ set at $8.0 / 8.0$; Fig. $\left.6 \mathrm{~d}\right)$. In these experiments, the local $\mathrm{pH}$ near the MsbA-NBD at the external side of the membrane remained constant. These data suggest that the conformational changes in MsbA-WT associated with ethidium transport can occur in the absence of ATP in a reaction driven by a $\Delta \mathrm{pH}$ and $\Delta \psi_{\mathrm{REV}}$. However, when ion gradients are imposed in the presence of ATP, proton coupling becomes functionally linked to ATP binding and hydrolysis, which are required to drive the dimerization and dissociation of the NBDs during the propagation of the transport cycle. Although the MsbA- $\Delta \mathrm{K} 382$ mutant can operate in a $\Delta \mathrm{pH}$-dependent manner in the absence of ATP, the addition of ATP traps this mutant in an ATP-bound state and renders it transport-inactive (Fig. 6e) in an analogous manner as observed in ATP-containing cells (Fig. 1c,d). This inhibitory trapping was mimicked by the addition of the non-hydrolysable AMP-PNP to MsbA-WT (Fig. 6a). The inhibitory effect of AMP-PNP on $\Delta \mathrm{pH}$-dependent ethidium accumulation in the proteoliposomes was not observed for MsbA-MD lacking the NBD (Fig. 6f).

MsbA-WT is more efficient than MsbA-MD. The observations on active drug transport by MsbA-MD raise questions about the functional importance of ATP binding and hydrolysis in fulllength MsbA. The direct comparison of the transport activities of MsbA-WT and MsbA-MD in cells show that MsbA-WT catalyses ethidium efflux to lower intracellular steady-state levels than MsbA-MD (Fig. 1c,d). When cell growth was measured in the presence of the MsbA substrate erythromycin ${ }^{15}$, MsbA protein expression caused significant shifts in the erythromycin concentration at which the growth rate is half-maximal $\left(\mathrm{IC}_{50}\right)$, from $0.004 \mu \mathrm{M}$ or the non-expressing control to $0.393 \mu \mathrm{M}$ $(P=0.008)$ for MsbA-WT and $0.094 \mu \mathrm{M}(P=0.003)$ for MsbA$\mathrm{MD}$; the $\mathrm{IC}_{50}$ for MsbA- $\Delta \mathrm{K} 382(0.051 \mu \mathrm{M})$ was close to control (Fig. 6g). Hence, the enhanced efficiency of efflux by full-length MsbA compared with the NBD-less protein was also found in the ability of the MsbA proteins to confer cellular resistance to the antibiotic erythromycin. The ATP-dependent dimerization of the NBDs with closure of the substrate-binding cavity towards the inside surface of the membrane facilitates capture of substrate from the cellular interior and/or inner membrane leaflet, and enables efflux against a larger drug concentration gradient and/or lipid-water partition coefficient. The ATP dependence therefore enhances the directionality of the transport reaction.

\section{Discussion}

Although MsbA is an ABC transporter that mediates substrate transport in an ATP-dependent manner, the experiments in intact cells and proteoliposomes prepared from E. coli phospholipids demonstrate for the first time that the ATP-bindingassociated power stroke during drug transport is assisted by proton coupling via apparent drug-proton antiport. The dissipation of the $\Delta \mathrm{pH}$ (interior alkaline) in cells by the addition of nigericin blocks MsbA-WT-mediated ethidium efflux (Fig. 1f). Conversely, the artificial imposition of the $\Delta \mathrm{pH}$ (inside acidic) in proteoliposomes initiates (i) the accumulation of ethidium and chloramphenicol by purified, inside-out oriented MsbA-WT above the equilibration level (Figs $4 c$ and 5a,b) and (ii) proton efflux in a chloramphenicol-dependent manner (Fig. $5 \mathrm{c}$ ). The role of the $\Delta \mathrm{pH}$ in MsbA-mediated transport in cells is also supported by the observations on the erythromycin efflux by MsbA-MD against the inwardly directed drug concentration gradient that impairs growth of the non-expressing control cells (Fig. 6g). Proton-coupled ethidium efflux by MsbA-WT is inhibited by the 
a

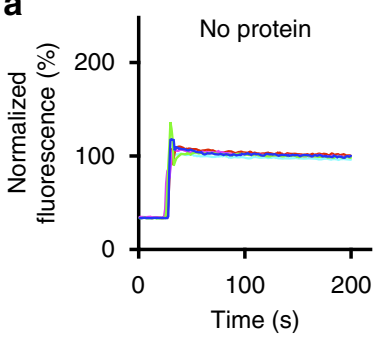

C

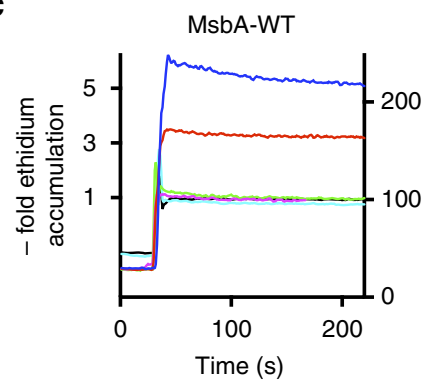

e

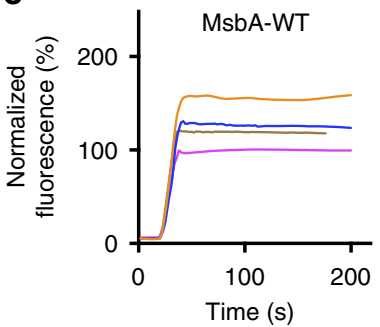

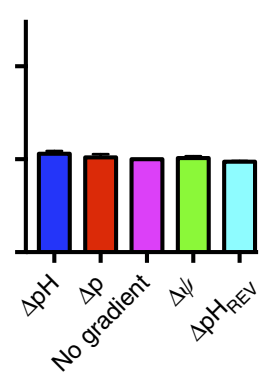
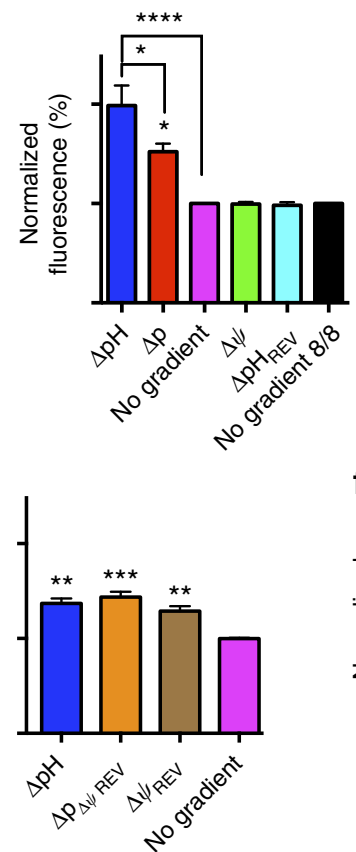

b

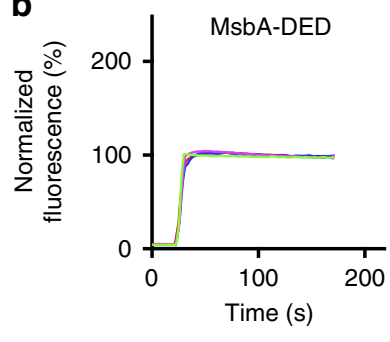

d
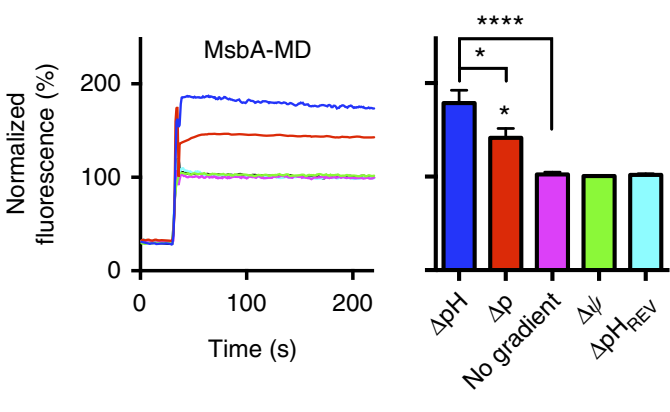

f
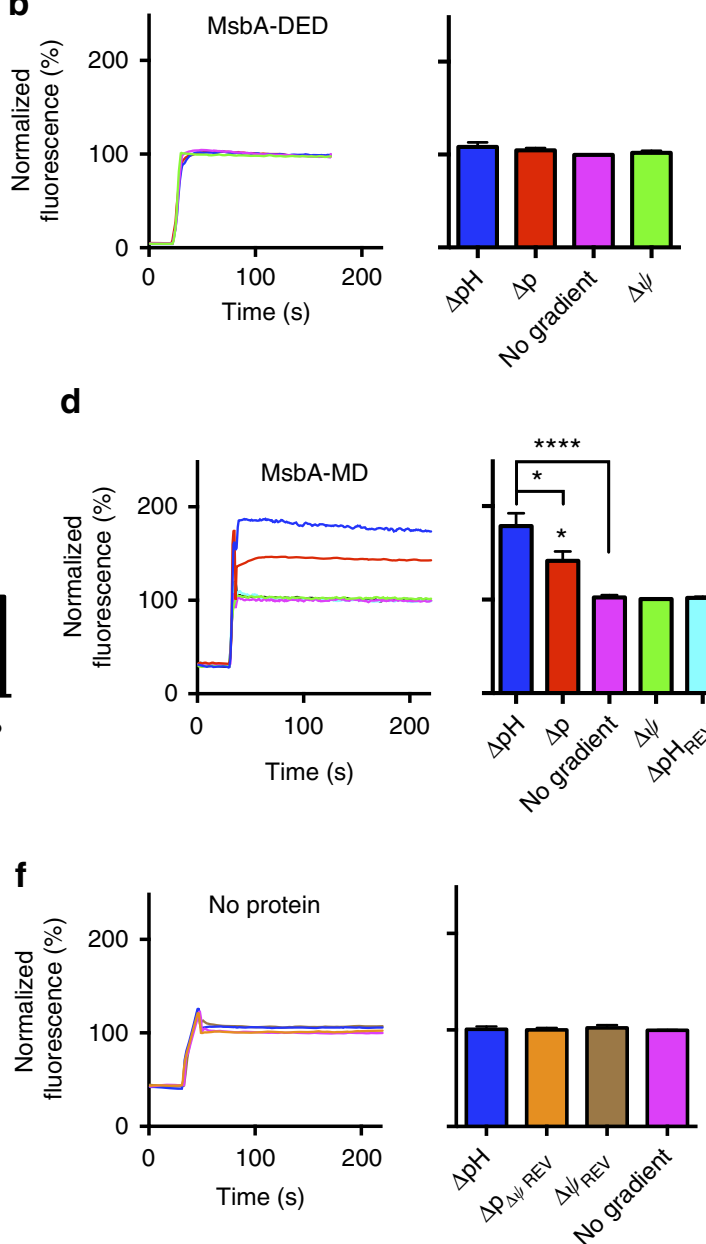

Figure 4 | Ethidium transport in proteoliposomes. (a-d) Ethidium transport in DNA-loaded empty liposomes (a) or proteoliposomes containing the MsbA-DED triple mutant (b), MsbA-WT (c) or MsbA-MD (d) with imposed $\Delta \mathrm{pH}\left(\mathrm{pH}_{\text {in }} 6.8 / \mathrm{pH}_{\text {out }} 8.0\right.$ ), $\Delta \psi$ (interior positive), proton-motive force $\left(\Delta p=\Delta \psi-Z \Delta p H\right.$ in which $Z$ equals $\sim 58 \mathrm{mV}$ at $\left.20^{\circ} \mathrm{C}\right), \Delta \mathrm{pH}_{\mathrm{REV}}\left(\mathrm{pH}_{\text {in }} 8.0 / \mathrm{pH}_{\text {out }} 6.8\right)$, or in the absence of ion gradients $\left(\mathrm{pH}_{\text {in }} 6.8 / \mathrm{pH}_{\text {out }} 6.8\right.$, termed $\mathrm{No}_{0}$ gradient and $\mathrm{pH}_{\text {in }} 8.0 / \mathrm{pH}_{\text {out }} 8.0$, No gradient $8 / 8$ ). No gradient $8 / 8$ for $(a, b, d)$ was very close to the No gradient control, and is not shown for clarity of presentation. The 5 -fold accumulation of ethidium by MsbA-WT is indicated in the fluorescence versus time graph in (c). (e,, $\mathbf{f})$ Effect of the imposition of a reversed $\Delta \psi_{R E V}$ (interior negative) without or with the $\Delta \mathrm{pH}$ (interior acidic) $\left(\Delta p_{\Delta \psi R E V}=\Delta \psi_{R E V}-Z \Delta p H\right.$ ) on ethidium transport in proteoliposomes containing MsbA-WT (e) or empty liposomes (f). Data represent observations in three or more independent experiments with independently prepared batches of proteoliposomes. Values in histograms show significance of fluorescence levels at steady-state, and are expressed as mean \pm s.e.m. (one-way analysis of variance; $\left.{ }^{\star} P<0.05 ;{ }^{\star \star} P<0.01 ;{ }^{\star \star *} P<0.001 ;{ }^{\star \star \star \star} P<0.0001\right)$.

$\Delta \psi$ (interior negative) in cells (Fig. 1f) and equivalent $\Delta \psi$ (interior positive) in the proteoliposomes (Fig. 4c). Together with the observed stimulation of transport in proteoliposomes by the $\Delta \psi_{\mathrm{REV}}$ (interior negative; Fig. 4e), the data point to apparent electrogenic antiport of ethidium ${ }^{+}$and $n \mathrm{H}^{+}$with $n<1$. Thus, two or more ethidium ${ }^{+}$molecules are exchanged per $\mathrm{H}^{+}$, which is consistent with the presence in this type of $\mathrm{ABC}$ transporter of two cavities at the MD-MD interface that are related by twofold pseudosymmetry and that can be separated by mutation ${ }^{10,24,26,27}$. Proton-coupled transport is associated with the MD of MsbA; the observations on $\Delta \mathrm{pH}$ dependence for MsbA-WT in intact cells and proteoliposomes could all be reproduced using MsbA-MD that lacks the NBD (Figs 1e and 4d).

Evidence was obtained that proton coupling operates in conjunction with a functional catalytic cycle at the NBDs when nucleotide is present. First, ethidium efflux in metabolically active cells containing mM concentrations of $\mathrm{ATP}^{21}$ was inhibited by the MsbA- $\Delta \mathrm{K} 382$ mutation (Fig. 1c). As the NBDs are conformationally coupled to the MDs, the reduced rate of ATP hydrolysis in the mutant will cause more persistent binding of the nucleotide, which in turn will block the propagation of the catalytic cycle, and, hence, inhibit transport. Second, for MsbA-WT this transport reaction in proteoliposomes was significantly inhibited by the inclusion of the non-hydrolysable ATP analogue AMP-PNP in the external buffer (Fig. 6a). Third, $\Delta \mathrm{pH}$ (interior acidic)-dependent ethidium accumulation in proteoliposomes by MsbA- $\Delta \mathrm{K} 382$ was inhibited by the addition of Mg-ATP to the external buffer where the NBDs reside (Fig. 6e). Fourth, the addition of ATP or AMP-PNP had no effect on $\Delta \mathrm{pH}$ (interior acidic)-dependent ethidium accumulation in proteoliposomes containing MsbA-MD without the NBD (Fig. 6f). Finally, the imposition of a $\Delta \mathrm{pH}$ stimulated the MsbA-WT ATPase activity in proteoliposomes (Fig. 6b-d). The dependence of drug transport on the genotype of the expressed or reconstituted MsbA proteins demonstrates that the drug transport activity is not dependent on auxiliary proteins but on MsbA itself. This conclusion is consistent with the mass spectrometry analysis demonstrating insignificant levels of contaminating membrane transporters or NBDs in our protein preparations (Fig. 2c). 
a
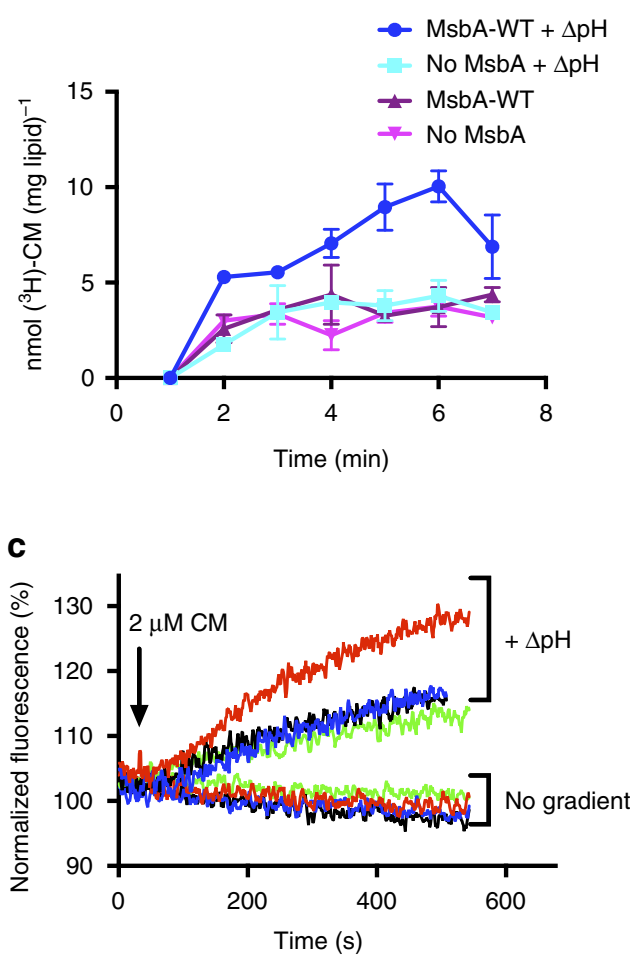

b
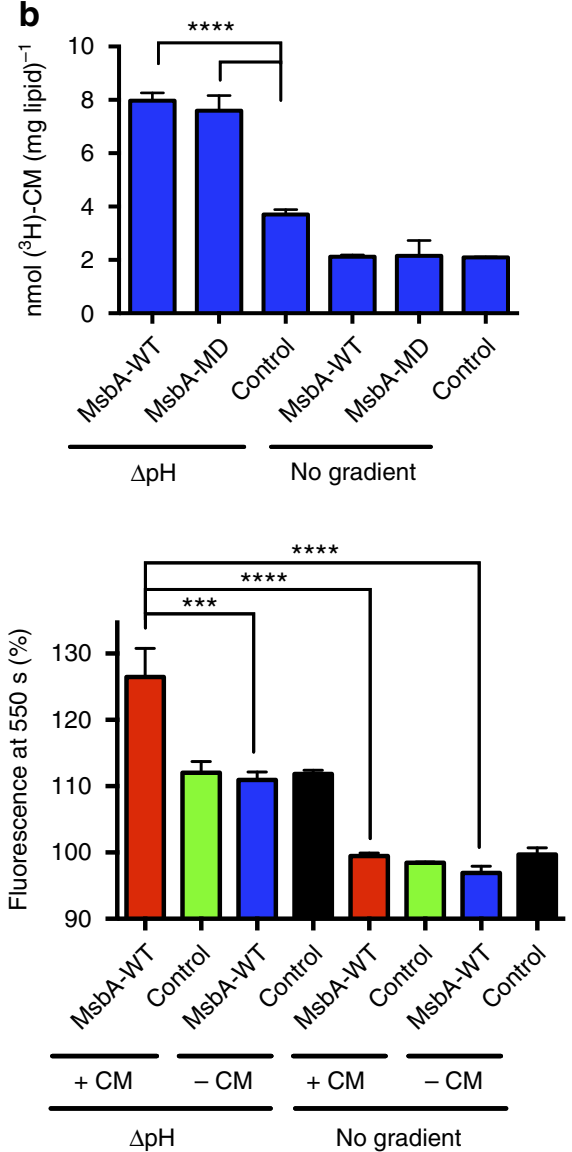

Figure 5 | Chloramphenicol/proton antiport in proteoliposomes. $(\mathbf{a}, \mathbf{b})$ Effect of the $\Delta \mathrm{pH}$ on the uptake of $2 \mu \mathrm{M}$ of the neutral antibiotic $\left[{ }^{3} \mathrm{H}\right]$-chloramphenicol $(\mathrm{CM})$ over time (a) and at $5 \mathrm{~min}(\mathbf{b})$ in proteoliposomes containing MsbA-WT or MsbA-MD, or in liposomes without MsbA proteins. (c) $\mathrm{CM}$ uptake by in proteoliposomes is associated with $\mathrm{H}^{+}$efflux through drug/proton antiport. The CM-dependent increase in fluorescence emission of the trapped pH probe BCECF in MsbA-WT-containing proteoliposomes but not in empty control liposomes indicates an increase in the lumen $\mathrm{pH}$ during the MsbA-WT catalysed reaction. Histogram shows BCECF fluorescence levels at $550 \mathrm{~s}$. The error bars for some of the data points in (a) were too small to be displayed, and are hidden behind the data point symbols. Data represent observations in three or more independent experiments with independently prepared batches of proteoliposomes. Values in histograms are expressed as mean \pm s.e.m. (one-way analysis of variance ; ${ }^{\star \star \star} P<0.001$; $\left.{ }^{\star \star \star \star} P<0.0001\right)$.

Protons can have different roles in the mechanisms of membrane transporters. A role of $\mathrm{H}^{+}$in primary-active transport was previously described for the P-type $\mathrm{Ca}^{2+}$-ATPase (SERCA), in which protons neutralize $\mathrm{Ca}^{2}{ }^{+}$-coordinating carboxylates following substrate dissociation, essentially giving primary-active transmembrane proton- $\mathrm{Ca}^{2+}$ antiport ${ }^{28,29} . \mathrm{H}^{+}$ binding and movement in proton-coupled secondary-active transporters are also known to induce changes in electrostatic and hydrogen-bonding interactions between interhelix side chains that underlie the conformational transitions associated with proton-substrate symport and antiport ${ }^{30,31}$. The finding of proton-coupled transport by MsbA suggests that similar mechanistic principles are relevant for $\mathrm{ABC}$ exporters. Indeed, recent structural studies on the antibacterial peptide $\mathrm{ABC}$ exporter McjD from $E$. coli conclude that the conformational transitions required for substrate transport might not all be dependent on ATP binding and hydrolysis ${ }^{32}$. The MsbA data share similarities with observations on the dual mode of energy coupling by the arsenite and antimonite-translocating ArsB protein from $E$. coli ${ }^{33,34}$, which acts as a secondary-active metalloid-proton antiporter, but when associated with the ArsA ATPase subunit can utilize ATP for improved extrusion efficiency. The findings for MsbA-MD are reminiscent to those described for the MD of the ABC exporter LmrA from L. lactis, which catalyses apparent ethidium-proton symport ${ }^{22,35}$ illustrating that the coupled transport of substrate and protons is more widespread among $\mathrm{ABC}$ exporters. Our conclusions introduce proton coupling as a new parameter in the mechanism of MsbA, and point to the existence of proton-coupled conformational transitions in its transport cycle. This work is of fundamental importance for our understanding of how $\mathrm{ABC}$ exporters operate.

\section{Methods}

Bacterial strains and plasmids. The drug-hypersensitive L. lactis strain NZ9000 $\triangle l m r A \triangle \operatorname{lm} r C D$ strain devoid of the endogenous ABC multidrug transporters $\mathrm{LmrA}$ and $\mathrm{LmrCD}^{36,37}$ was used as a host for expression vector pNZ8048-derived plasmids ${ }^{36}$ that contain a chloramphenicol resistance marker gene, nisin-inducible nisA promoter and His-tagged wild-type (WT) or mutant MsbA gene, or truncated MsbA gene encoding the MD only.

Construction of MsbA mutants. To express $\mathrm{N}$ terminally His-tagged MsbA-MD, the corresponding region of the $m s b A$ gene from $E$. coli was PCR-amplified from pNZMsbA ${ }^{15}$ with the forward primer $5^{\prime}$-GGAGGCACTCACCATGGGC- $3^{\prime}$ and the reverse primer $5^{\prime}$-CGGATAAGTTCTAGATTAATTGCGGAATTCCACGT CGGC- $3^{\prime}$ to insert a TAA stop codon after the codon for N346, equivalent to H353 in previous work on $\mathrm{LmrA}^{22}$, followed by an XbaI site at the $3^{\prime}$ end. NcoI and XbaI (Roche Applied Science, Herts, UK) were used to digest the PCR product, which was followed by ligation of the DNA fragment into the linearized vector pNZ8048 downstream of the nisA promoter, yielding pNZMsbA-MD. For the generation of 

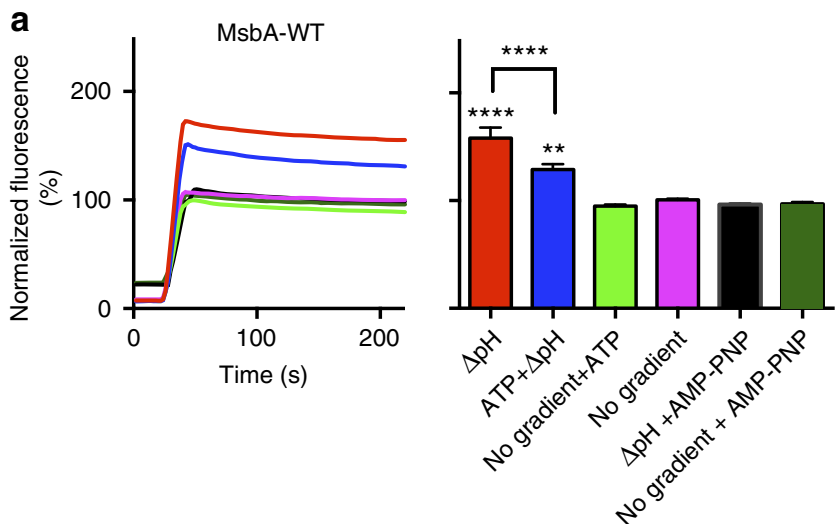

b

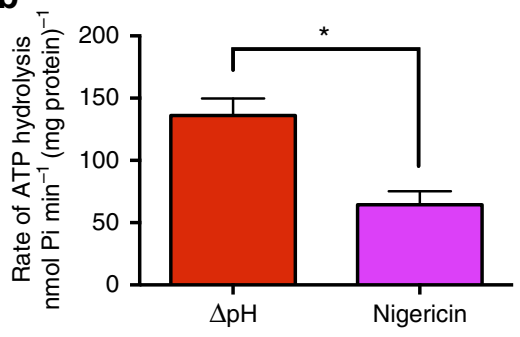

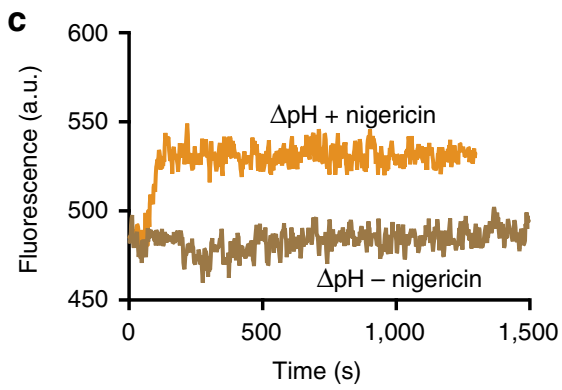

e

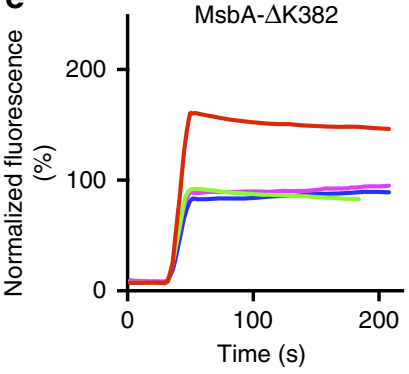

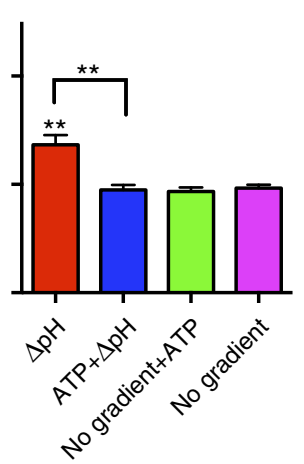

d

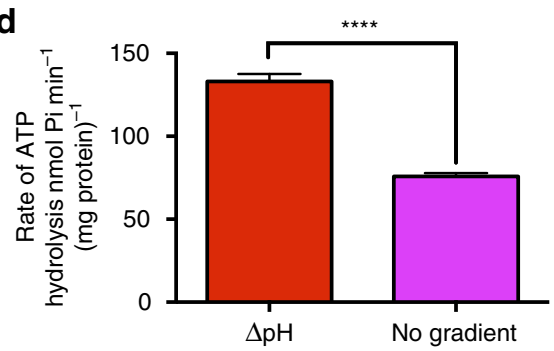

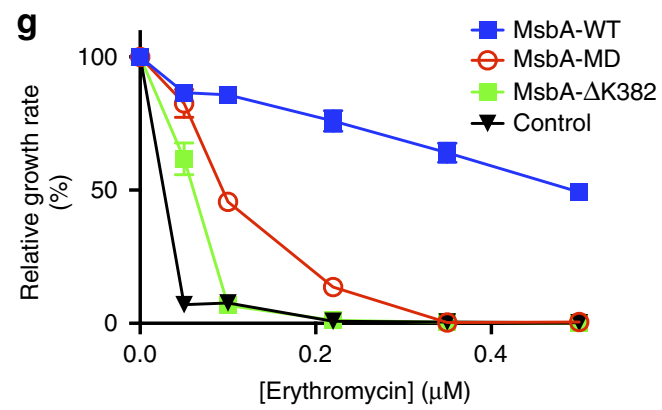

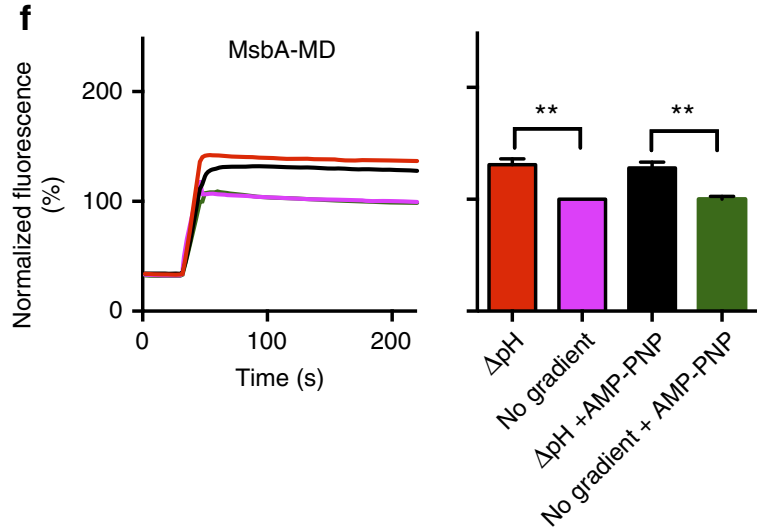

Figure 6 | Relationship between ATP dependence and proton coupling by MsbA proteins. (a) Effect of the presence of $2.5 \mathrm{~mm}$ Mg-ATP or non-hydrolyzable nucleotide analogue AMP-PNP on imposed $\Delta \mathrm{pH}\left(\mathrm{pH}_{\text {in }} 6.8 / \mathrm{pH}_{\text {out }} 8.0\right)$-dependent ethidium transport by MsbA-WT in DNA-loaded proteoliposomes. Histogram shows significance of fluorescence levels at steady-state. (b,c) MsbA-WT ATPase activity in proteoliposomes in which the $\Delta \mathrm{pH}\left(\mathrm{pH}_{\text {in }} 6.8 / \mathrm{pH}_{\text {out }} 8.0\right.$ ) was dissipated in the presence of nigericin (leading to $\mathrm{pH}_{\text {in }} 8.0 / \mathrm{pH}_{\text {out }} 8.0$ ) (b). This action of nigericin was confirmed using proteoliposomes $\left(\mathrm{pH}_{\text {in }} 6.8 / \mathrm{pH}_{\text {out }} 8.0\right)$ loaded with the $\mathrm{pH}$ probe BCECF (brown trace), the fluorescence emission of which was enhanced by the increase in the lumen $\mathrm{pH}$ from 6.8 to 8.0 by the addition of the ionophore at $t=0 \mathrm{~s}$ (orange trace) (c). (d) MsbA-WT ATPase activity in proteoliposomes in the presence of an imposed $\Delta \mathrm{pH}\left(\mathrm{pH}_{\text {in }} 6.8 / \mathrm{pH}_{\text {out }} 8.0\right)$ or its absence $\left(\mathrm{pH}_{\text {in }} 8.0 / \mathrm{pH}_{\text {out }} 8.0\right)$. Note that the $\mathrm{pH}$ near the NBD of MsbA (at the external side of the proteoliposomes) remains constant in the experiments displayed in (b) and (d). (e,f) Experiments as described in (a) in proteoliposomes containing MsbA- $\Delta$ K382 (e) or MsbA-MD (f). (g) Erythromycin resistance in cells expressing MsbA-WT (blue squares), MsbA-MD (red circles), MsbA- $\Delta K 382$ (green squres) compared to non-expressing control cells (black triangles). Maximum specific growth rate $\left(\mu_{\max }\right)$ was determined at each erythromycin concentration and is presented as a percentage of $\mu_{\max }$ in the absence of erythromycin. The error bars for some of the data points in ( $\mathbf{g}$ ) were too small to be displayed, and are hidden behind the data point symbols. Data represent observations in 3 or more independent experiments with independently prepared batches of proteoliposomes or cells. Values in histograms are expressed as mean \pm s.e.m. (one-way analysis of variance except for (b,d) unpaired student- $t$ test; $\left.{ }^{\star} P<0.05 ;{ }^{\star \star} P<0.01 ;{ }^{\star \star \star \star} P<0.0001\right)$. 
pNZMsbA-DED (D41N E149Q D252N) the following primers were used: D41N (forward) 5'-GCCAGCAACACCTTCATGTTATCGCTCC-3' , (reversed) 5'-AAG GTGTTGCTGGCTGCGTTGAGGATTA-3'; E149Q (forward) 5' -TGTGCGTCAA GGTGCGTCGATCATCGGC-3' ${ }^{\prime}$, (reversed) $5^{\prime}$-ACGCACCTTGACGCACAACAG TAATCAG-3'; D252N (forward) 5'-CATCTCTAATCCGATCATTCAGCTG ATC- ${ }^{\prime}$, (reversed) $5^{\prime}$-TGATCGGATTAGAGATGGAAGAGGCTGA- $3^{\prime}$. The DNA was sequenced to ensure that only the intended changes were introduced.

Growth conditions and protein expression. L. lactis NZ9000 $\Delta l m r A \Delta l m r C D$ was grown overnight in M17 medium (Difco) supplemented with $0.5 \%$ glucose and $5 \mu \mathrm{g} \mathrm{ml}^{-1}$ chloramphenicol at $30^{\circ} \mathrm{C}$ to an $\mathrm{OD}_{660}$ of $0.5-0.6$. For protein expression, cells harbouring pNZMsbA, pNZMsbA-MD, pNZMsbA- $\Delta$ K382 (ref. 16), pNZMsbA-DED or pNZ8048 (empty vector) were incubated for $1 \mathrm{~h}$ at $30^{\circ} \mathrm{C}$ in the presence of a 1:1,000 dilution of the culture supernatant of nisin-A producing L. lactis strain NZ9700, corresponding to a nisin A concentration of $\sim 10 \mathrm{pg} \mathrm{ml}^{-1}$ (ref. 38), unless stated otherwise.

Ethidium transport in de-energized cells. L. lactis NZ9000 $\Delta l m r A \Delta l m r C D$ cells expressing MsbA, MsbA- $\Delta \mathrm{K} 382$ or MsbA-MD and non-expressing control cells were grown to an $\mathrm{OD}_{660}$ of 0.6 , and protein expression was induced for $1 \mathrm{~h}$ at $30^{\circ} \mathrm{C}$ by $10 \mathrm{pg} \mathrm{ml}^{-1}$ nisin A. Cell pellets from $50 \mathrm{ml}$ culture were harvested by centrifugation $\left(6,500 \mathrm{~g}\right.$ for $10 \mathrm{~min}$ at $\left.4{ }^{\circ} \mathrm{C}\right)$ and washed with ice-cold washing buffer $\left(50 \mathrm{~mm} \mathrm{KPi}, \mathrm{pH} 7.0\right.$, containing $5 \mathrm{~mm} \mathrm{MgSO}_{4}$ ). To deplete intracellular ATP levels, cells were incubated with $0.5 \mathrm{mM}$ of the protonophore 2,4-dinitrophenol for $30 \mathrm{~min}$ at $30^{\circ} \mathrm{C}$. The protonophore was removed by centrifugation, followed by washing of cells with the washing buffer. Finally, the cells were resuspended in washing buffer to an $\mathrm{OD}_{660}$ of 5.0. For each measurement, cells were diluted at 1:10 into $2 \mathrm{ml}$ washing buffer in a glass cuvette. Fluorescence was followed in a LS 55B Luminescence Spectrometer (PerkinElmer, MA, USA) at excitation and emission wavelengths of 500 and $580 \mathrm{~nm}$ with slit widths of 10 and $5 \mathrm{~nm}$, respectively. Owing to differences in the uptake rates, ATP-depleted control cells and cells containing MsbA-WT or MsbA-MD were pre-loaded with $2 \mu \mathrm{M}$ ethidium bromide for 50, 25 and $30 \mathrm{~min}$, respectively, to a similar starting fluorescence level. Active efflux was subsequently initiated by the addition of $0.5 \%$ glucose, which re-energized the cells and fluorescence was followed for $\sim 10 \mathrm{~min}$. To further determine the influence of the magnitude and composition of the $\Delta p$ on MsbA-mediated transport, ionophores nigericin and valinomycin were added (final concentration 1 and $0.1 \mu \mathrm{M}$, respectively) before activation of cells. When cells are suspended in high $\mathrm{K}^{+}$containing buffer, nigericin mediates the antiport of $\mathrm{H}^{+}$ and $\mathrm{K}^{+}$down their concentration gradients, thereby selectively dissipating $\Delta \mathrm{pH}$ in an electroneutral manner. Furthermore, valinomycin mediates electrogenic uniport of $\mathrm{K}^{+}$, allowing the electrophoretic uptake of $\mathrm{K}^{+}$in cells with dissipation of the $\Delta \psi$ (ref. 39).

Preparation of inside-out membrane vesicles. Inside-out membrane vesicles were prepared from L. lactis NZ9000 $\Delta l m r A \Delta l m r C D$ cells harbouring pNZ8048based expression vectors using cell disruption equipment ${ }^{15}$. For this purpose, lactococcal cells were grown at $30^{\circ} \mathrm{C}$ to an $\mathrm{OD}_{660}$ of $0.6-0.8$ and incubated for $1 \mathrm{~h}$ in the presence of nisin A to induce protein expression. Cells were then harvested by centrifugation at $13,000 \mathrm{~g}, 12 \mathrm{~min}, 4^{\circ} \mathrm{C}$ and washed with ice-cold $100 \mathrm{~mm} \mathrm{KPi}$ ( $\mathrm{pH} 7.0$ ) or $100 \mathrm{~mm}$ K-HEPES ( $\mathrm{pH}$ 7.0) when the vesicles were prepared to measure ATPase activity. The cell pellet was resuspended in $20 \mathrm{~mm} \mathrm{KPi} / \mathrm{K}-\mathrm{HEPES}$ containing Complete-Protease Inhibitor Cocktail (Roche) followed by the addition of $3 \mathrm{mg} \mathrm{ml}^{-1}$ lysozyme (from chicken egg white) and further incubation for $30 \mathrm{~min}$ at $30^{\circ} \mathrm{C}$. Cell lysis was achieved by passage twice through a Basic Z $0.75 \mathrm{~kW}$ Benchtop Cell Disruptor (Constant Systems, Northlands, UK) at $20 \mathrm{kpsi}$. The suspension was supplemented with $10 \mu \mathrm{g} \mathrm{ml}^{-1}$ DNase and $10 \mathrm{mM} \mathrm{MgSO}_{4}$ andincubated for $30 \mathrm{~min}$ at $30^{\circ} \mathrm{C}$ to remove DNA. Subsequently, $15 \mathrm{~mm}$ K-EDTA $(\mathrm{pH} 7.0)$ was added to prevent the aggregation of membrane vesicles. A low spin at $13,000 \mathrm{~g}$ for $40 \mathrm{~min}$ was performed to remove cell debris and whole cells. Membrane vesicles were harvested from the supernatant by ultra-centrifugation at $125,000 \mathrm{~g}$ for $1 \mathrm{~h}$ at $4{ }^{\circ} \mathrm{C}$. The membrane vesicles were resuspended in $50 \mathrm{mM} \mathrm{KPi} / \mathrm{K}$-HEPES (pH 7.0) containing $10 \%$ glycerol and stored as $500 \mu \mathrm{l}$ aliquots in liquid nitrogen. The expression of MsbA proteins in membrane vesicles was assessed on Coomassie-stained SDS-PAGE, and immunoblots probed with primary mouse anti-polyhistidine tag antibody (Sigma-Aldrich, cat. no.: H1029) and secondary goat antimouse antibody (Sigma-Aldrich, cat. no.: A4416) were used at dilutions of 1:1,000 and 1:5,000, respectively (Supplementary Fig. 1).

Purification of His-tagged MsbA proteins. His-tagged MsbA proteins were purified from membrane vesicles by $\mathrm{Ni}^{2+}$-nitrilotriacetic acid (NTA) affinity chromatography ${ }^{7,24,38}$. Membrane vesicles (diluted to $5 \mathrm{mg} \mathrm{ml}^{-1}$ ) were solubilized in buffer containing $50 \mathrm{~mm} \mathrm{KPi}$ or K-HEPES ( $\mathrm{pH} 8.0), 10 \%(\mathrm{v} / \mathrm{v})$ glycerol, $0.1 \mathrm{M}$ $\mathrm{NaCl}$ and $1 \%(\mathrm{w} / \mathrm{v}) \mathrm{n}$-dodecyl- $\beta$-D-maltoside (DDM) (Melford Laboratories Ltd., UK) for $4 \mathrm{~h}$ by gently mixing on a rotating wheel at $4{ }^{\circ} \mathrm{C}$. Insoluble particles were removed by centrifuging the mixture at $125,000 \mathrm{~g}, 4^{\circ} \mathrm{C}$ for $40 \mathrm{~min}$. The solubilized protein was mixed with $\mathrm{Ni}^{2+}$-NTA resin at a ratio of $10 \mathrm{mg}$ His-tagged protein per $\mathrm{ml}$ of resin. The resin was pre-equilibrated by washing thrice with five resin volumes of Milli Q water and twice with five resin volumes of wash Buffer A
(50 mм KPi or K-HEPES (pH 8.0), $0.1 \mathrm{M} \mathrm{NaCl}, 10 \%(\mathrm{v} / \mathrm{v})$ glycerol, $0.05 \%(\mathrm{w} / \mathrm{v})$ DDM and $20 \mathrm{~mm}$ imidazole). The suspension was left on a rotating wheel for overnight binding at $4^{\circ} \mathrm{C}$, after which the resin was collected by centrifugation and transferred to a $2 \mathrm{ml}$ volume Biospin disposable chromatography column (Bio-Rad). After subsequent washing with 20 volumes of wash Buffer A and 30 volumes of wash Buffer B (50 mu KPi or K-HEPES (pH 7.0), $0.1 \mathrm{M} \mathrm{NaCl}, 10 \%(\mathrm{v} / \mathrm{v})$ glycerol, $0.05 \%(\mathrm{w} / \mathrm{v}) \mathrm{DDM}$ and $20 \mathrm{~mm}$ imidazole added from $1 \mathrm{M}$ imidazole stock ( $\mathrm{pH} 8.0)$ ), His-tagged protein was eluted with 3-4 volumes of Elution Buffer (50 mM KPi or K-HEPES (pH 7.0), $0.1 \mathrm{M} \mathrm{NaCl}, 5 \%(\mathrm{v} / \mathrm{v})$ glycerol, $0.05 \%(\mathrm{w} / \mathrm{v})$ DDM and $150 \mathrm{~mm}$ imidazole added from $1 \mathrm{M}$ imidazole stock ( $\mathrm{pH}$ 8.0)). The eluted purified protein was kept on ice and was immediately used for experiments. Purity of the protein was monitored on a 10\% SDS-PAGE with Coomassie Brilliant Blue staining.

LC-MS/MS mass spectrometry analysis. Purified MsbA proteins were reduced (DTT) and alkylated (iodoacetamide) and subjected to enzymatic digestion with trypsin overnight at $37^{\circ} \mathrm{C}$. Aliquots were then pipetted into a sample vial and loaded onto an autosampler for automated LC-MS/MS analysis ${ }^{40}$. All LC-MS/MS experiments were performed using a nanoAcquity UPLC (Waters Corp., Milford, MA) system and an LTQ Orbitrap Velos hybrid ion trap mass spectrometer (Thermo Scientific, Waltham, MA). Separation of peptides was performed by reverse-phase chromatography using a Waters reverse-phase nanocolumn (BEH C18, $75 \mu \mathrm{m}$ inner diameter $\times 250 \mathrm{~mm}, 1.7 \mu \mathrm{m}$ particle size) at flow rate of $300 \mathrm{nl} \mathrm{min}^{-1}$. Peptides were initially loaded onto a pre-column (Waters UPLC Trap Symmetry C18, $180 \mu \mathrm{m}$ inner diameter $\times 20 \mathrm{~mm}, 5 \mu \mathrm{m}$ particle size) from the nanoAcquity sample manager with $0.1 \%$ formic acid for $5 \mathrm{~min}$ at a flow rate of $5 \mu \mathrm{min}^{-1}$. After this period, the column valve was switched to allow the elution of peptides from the pre-column onto the analytical column. Solvent A was water $+0.1 \%$ formic acid and solvent $\mathrm{B}$ was acetonitrile $+0.1 \%$ formic acid. The linear gradient employed was 5-40\% B in $40 \mathrm{~min}$ (total LC-MS/MS run time was $60 \mathrm{~min}$ ). The LC eluant was sprayed into the mass spectrometer by means of a New Objective nanospray source. All $\mathrm{m} / \mathrm{z}$ values of eluting ions were measured in the Orbitrap Velos mass analyser, set at a resolution of 30,000. Data dependent scans (Top 20) were employed to automatically isolate and generate fragment ions by collision-induced dissociation in the linear ion trap, resulting in the generation of MS/MS spectra. Ions with charge states of $2+$ and above were selected for fragmentation. Post run, the data were processed using Protein Discoverer (version 1.4., ThermoFisher). Briefly, all MS/MS data were converted to mgf files and these files were then submitted to the Mascot search algorithm (Matrix Science, London, UK) and searched against the Uniprot L. lactis subsp. lactis strain IL1403 database (taxon identifier 1360) using a fixed modification of carbamidomethyl (C), variable modifications of oxidation $(\mathrm{M})$ and deamidation $(\mathrm{NQ})$. The peptide mass tolerance was set to $25 \mathrm{ppm}$, the fragment ion mass tolerance to $0.8 \mathrm{Da}$ and the maximum number of missed cleavages to 2 .

Reconstitution of purified MsbA proteins. Purified protein (MsbA-WT, MsbA- $\Delta \mathrm{K} 382$, MsbA-DED or MsbA-MD) was reconstituted in proteoliposomes prepared from acetone-ether-washed $E$. coli phospholipids $7,38,41$ diluted to $4 \mathrm{mg} \mathrm{ml}^{-1}$ in chloroform, which were mixed in a ratio of $3: 1(\mathrm{w} / \mathrm{w})$ with egg-yolk phosphatidylcholine (Avanti Polar Lipids Inc.). Solvent was evaporated using $\mathrm{N}_{2}$ gas after which the lipid mixture was rehydrated using Buffer 1 (10 mM K-HEPES (pH 6.8), $10 \mathrm{~mm}$ Tris-Cl, $100 \mathrm{~mm} \mathrm{~K}_{2} \mathrm{SO}_{4}$ and $\left.100 \mathrm{~mm} \mathrm{NH}_{4} \mathrm{SCN}\right)$ or Buffer $2(10 \mathrm{~mm}$ Tris-Cl ( $\mathrm{pH}$ 8.0), $10 \mathrm{~mm}$ K-HEPES and $100 \mathrm{~mm}$ KSCN; see under 'Substrate transport in proteoliposomes'), and $1 \mathrm{mg} \mathrm{ml}^{-1}$ of sonicated calf thymus DNA (Trevigen) for ethidium transport measurements. After resuspension, lipids were extruded 11 times through a 400-nm polycarbonate filter to form unilamellar liposomes of homogenous size and destabilized by the step-wise addition of Triton $\mathrm{X}-100$ which was followed at $\mathrm{OD}_{540}$ (ref. 38). For reconstitution, purified protein was mixed with the detergent-destabilized liposomes in a 1/50 ratio $(\mathrm{w} / \mathrm{w})$ and incubated at room temperature (RT) for $30 \mathrm{~min}$. Detergent was then removed using polystyrene bio-beads (Bio-Bead SM-2, Bio-Rad). For this purpose, Bio-Beads were pre-washed three times with methanol, once with ethanol and five times with water before use. Successive extractions of detergent were achieved by incubating proteoliposomes, first with $80 \mathrm{mg} \mathrm{ml}^{-1}$ Bio-Beads for $2 \mathrm{~h}$ at RT, then with $8 \mathrm{mg} \mathrm{ml}^{-1}$ Bio-Beads for $2 \mathrm{~h}$ at $4^{\circ} \mathrm{C}$ and finally with $8 \mathrm{mg} \mathrm{ml}^{-1}$ Bio-Beads for $18 \mathrm{~h}$ at $4^{\circ} \mathrm{C}$. Proteoliposomes were harvested by centrifugation $(130,000 \mathrm{~g}$ for $30 \mathrm{~min}$, $4^{\circ} \mathrm{C}$ ), resuspended in $3 \mathrm{ml} \mathrm{Buffer} 1$ or 2 , in which the liposomes were prepared, and incubated at $30^{\circ} \mathrm{C}$ for $20 \mathrm{~min}$ with $10 \mathrm{mM} \mathrm{MgSO}_{4}$ and $10 \mu \mathrm{g} \mathrm{ml}^{-1}$ DNase to remove any DNA contamination from the lipid bilayer. Finally, liposomes were harvested by centrifugation $\left(130,000 \mathrm{~g}\right.$ for $\left.30 \mathrm{~min}, 4^{\circ} \mathrm{C}\right)$, resuspended in $150-200 \mu \mathrm{l}$ Buffer 1 or 2 that was used for their preparation and used immediately for transport studies. Samples were maintained on ice.

Substrate transport in proteoliposomes. Ethidium transport measurements with reconstituted proteoliposomes containing MsbA proteins were initiated by the 100 -fold dilution of DNA-loaded proteoliposomes in $2 \mathrm{ml}$ of external buffer in a $3-\mathrm{ml}$ fluorescence cuvette (to a final concentration of $20 \mu \mathrm{g}$ membrane protein per $\mathrm{ml}$ ) to impose different electrochemical ion gradients. For this purpose, proteoliposomes in Buffer 1 (see under 'Reconstitution of purified MsbA proteins') 
were diluted 100-fold in Buffer i (10 mM K-HEPES ( $\mathrm{pH}$ 8.0), $10 \mathrm{~mm}$ Tris-Cl and $\left.100 \mathrm{~mm} \mathrm{~K}_{2} \mathrm{SO}_{4}\right)$ to impose the $\Delta p$ (interior positive and acidic), Buffer ii $(10 \mathrm{~mm}$ K-HEPES ( $\mathrm{pH}$ 8.0), $10 \mathrm{~mm}$ Tris-Cl and $100 \mathrm{~mm} \mathrm{KSCN}$ ) to impose the $\Delta \mathrm{pH}$ (interior acidic), or Buffer iii (10 mM K-HEPES (pH 6.8), $10 \mathrm{~mm}$ Tris-Cl, $50 \mathrm{~mm}\left(\mathrm{NH}_{4}\right)_{2} \mathrm{SO}_{4}$ and $100 \mathrm{~mm} \mathrm{~K}_{2} \mathrm{SO}_{4}$ ) to impose the $\Delta \psi$ (interior positive). In experiments with the $\Delta \psi_{\mathrm{REV}}$, proteoliposomes in Buffer 2 (see under 'Reconstitution of purified MsbA proteins') were diluted 100-fold into Buffer iv (10 mM NMG-HEPES (pH 6.8), $10 \mathrm{~mm}$ Tris-Cl and $\left.50 \mathrm{~mm}\left(\mathrm{NH}_{4}\right)_{2} \mathrm{SO}_{4}\right)$ in the presence of $10 \mathrm{nmol}$ per mg protein of valinomycin to impose the $\Delta \psi_{\mathrm{REV}}$ (interior negative), Buffer $\mathrm{v}$ (10 mM K-HEPES ( $\mathrm{pH} 8.0$ ), $10 \mathrm{~mm}$ Tris- $\mathrm{Cl}$ and $50 \mathrm{~mm} \mathrm{~K}_{2} \mathrm{SO}_{4}$ ) to impose the $\Delta \mathrm{pH}$ (interior acidic), or Buffer vi (10 mM NMG-HEPES ( $\mathrm{pH} 8.0)$ and $10 \mathrm{~mm}$ Tris-Cl) in the presence $10 \mathrm{nmol}$ per mg protein valinomycin to impose the $\Delta p_{\Delta \psi \mathrm{REV}}$ (interior negative and acidic). After $30 \mathrm{~s}$ of recording, ethidium bromide $(2 \mu \mathrm{M})$ was added and fluorescence was measured as a function of time in an LS 55B luminescence spectrometer (Perkin-Elmer Life Sciences) with excitation and emission wavelengths of 500 and $580 \mathrm{~nm}$ with slit widths of 10 and $5 \mathrm{~nm}$, respectively. In control experiments, proteoliposomes were diluted 100 -fold in the buffer in which they were prepared $\left(\mathrm{pH}_{\text {in }} 6.8 / \mathrm{pH}_{\text {out }} 6.8\right.$ and $\left.\mathrm{pH}_{\text {in }} 8.0 / \mathrm{pH}_{\text {out }} 8.0\right)$ to measure ethidium transport in the absence of ion gradients. In addition, empty liposomes were prepared with nickel NTA elution buffer instead of purified protein, and these were diluted in the same buffers as the proteoliposomes.

For measurements of $\Delta \mathrm{pH}$ (interior acidic)-dependent chloramphenicol transport, proteoliposomes were generated as described for ethidium transport, but without DNA in the internal lumen, and diluted 100-fold (to $30 \mu \mathrm{g}$ phospholipid per $\mathrm{ml}$ ) in $500 \mu \mathrm{l}$ dilution buffer in glass tubes containing $2 \mu \mathrm{M}$ $\left[{ }^{3} \mathrm{H}\right]$-chloramphenicol $\left(3.33 \mathrm{TBq} \mathrm{mol}^{-1}\right)$ (Sigma). At given time intervals, samples were withdrawn, diluted with $2 \mathrm{ml}$ of ice-cold $0.1 \mathrm{M}$ lithium chloride, filtered immediately through cellulose nitrate filters $(0.45 \mu \mathrm{m}$ pore size $)$ and washed once with $2 \mathrm{ml}$ of the lithium chloride solution. Radioactivity retained on the filters was measured by liquid scintillation counting. Transport data were corrected for binding of chloramphenicol to the nitrocellulose filters. To provide evidence for proton-coupled chloramphenicol transport by MsbA-WT, (proteo)liposomes were prepared in Buffer 1 (interior acidic; $\mathrm{pH}$ 6.8) containing $100 \mu \mathrm{M}$ of the $\mathrm{pH}$ indicator BCECF (Molecular Probes). These (proteo)liposomes were diluted 100fold in Buffer ii ( $\mathrm{pH}$ 8.0) to impose $\mathrm{a} \mathrm{H}^{+}$gradient, or Buffer 1 for control measurements in the absence of an ion gradient. BCECF fluorescence was measured with wavelengths for excitation at $502 \mathrm{~nm}$ and emission at $525 \mathrm{~nm}$, and with slit widths of 10 and $15 \mathrm{~nm}$, respectively. Experiments were performed in triplicate using independent batches of proteoliposomes.

ATPase activity in proteoliposomes. The ATPase activity of MsbA was monitored in reconstituted proteoliposomes in the absence or presence of the $\Delta \mathrm{pH}$, using the Malachite Green assay to measure the liberation of Pi over time ${ }^{37,42}$. Proteoliposomes prepared in Buffer 1 were diluted 20 -fold in Buffer ii as described under 'Substrate transport in proteoliposomes' (Fig. 6b). To dissipate the $\Delta \mathrm{pH}, 1 \mu \mathrm{M}$ nigericin was added immediately after dilution of proteoliposomes, and the mixture was kept on ice for 5 min before the measurements of ATPase activity. The ATPase reaction was started by the addition of $2.5 \mathrm{~mm} \mathrm{Mg-ATP} \mathrm{(high} \mathrm{grade}$ ATP from Sigma), after which Pi release was measured at 1 and 2 min. Following incubation at $30^{\circ} \mathrm{C}$, the reactions were stopped by mixing $30-\mu \mathrm{l}$ aliquots with activated malachite green-ammonium molybdate for $5 \mathrm{~min}$ in a 96 -well plate. Samples were subsequently incubated for 25 min with $34 \%$ citric acid after which the $\mathrm{OD}_{600}$ was determined. Pi release between $t=1 \mathrm{~min}$ and $t=2 \mathrm{~min}$ was calculated. To confirm that nigericin was able to dissipate the $\Delta \mathrm{pH}, 100 \mu \mathrm{M} \mathrm{BCECF}$ was added to the preparation Buffer 1 to include the probe in the lumen of the proteoliposomes (Fig. 6c). BCECF fluorescence emission was measured in a LS 55B luminescence spectrometer with excitation and emission wavelengths of 535 and $590 \mathrm{~nm}$ with slit widths of 10 and $5 \mathrm{~nm}$, respectively. For the experiments in Fig. 6d, proteoliposomes prepared in buffer ( $\mathrm{pH} 6.8$ or 8.0 ) containing $10 \mathrm{~mm}$ Tris-Cl and $10 \mathrm{~mm}$ K-HEPES were diluted 20 -fold in buffer ( $\mathrm{pH} 8.0$ ) containing $10 \mathrm{~mm}$ Tris-Cl and $10 \mathrm{mM} \mathrm{K}$-HEPES.

Orientation of MsbA in the membrane. Right-side-out membrane vesicles were prepared by osmotic lysis of cells ${ }^{43}$. MsbA-WT expressing lactococcal cells from 11 culture were collected by centrifugation at $13,000 \mathrm{~g}$ for $15 \mathrm{~min}$ at $4{ }^{\circ} \mathrm{C}$. The pellet was washed once in $100 \mathrm{~mm} \mathrm{KPi} \mathrm{(pH} \mathrm{7.0).} \mathrm{Cells} \mathrm{were} \mathrm{resuspended} \mathrm{in} 5 \mathrm{ml}$ of the same buffer containing half a tablet of complete protease inhibitor cocktail (Roche Applied Science), $10 \mathrm{~mm} \mathrm{MgSO} 4,40 \mathrm{mg} \mathrm{ml}^{-1}$ lysozyme, and were incubated for $30 \mathrm{~min}$ at $30^{\circ} \mathrm{C}$ under mild shaking. The protoplast suspension was mixed with $4.8 \mathrm{ml}$ of a $0.75 \mathrm{M} \mathrm{K}_{2} \mathrm{SO}_{4}, 10 \mu \mathrm{g} \mathrm{ml}^{-1}$ DNase and RNase while stirring, and incubated for $2 \mathrm{~min}$ at $30^{\circ} \mathrm{C}$. The homogenized, concentrated protoplast suspension was poured directly into $36 \mathrm{ml} 100 \mathrm{mM} \mathrm{KPi} \mathrm{(pH} \mathrm{7.0).} \mathrm{The} \mathrm{lysate} \mathrm{was}$ incubated for $20 \mathrm{~min}$ at $30^{\circ} \mathrm{C}$ with vigorous swirling. K-EDTA, pH 7.0, was then added to $20 \mathrm{~mm}$ final concentration, and the incubation was continued for $10 \mathrm{~min}$ at $30^{\circ} \mathrm{C}$. Shortly after the addition of EDTA, the turbidity of the suspension decreased and the viscosity increased. Finally, $\mathrm{MgSO}_{4}$ was added to a final concentration of $15 \mathrm{~mm}$ and the incubation was continued for another $15 \mathrm{~min}$ at $30^{\circ} \mathrm{C}$; during this period the viscosity decreased. The lysates were centrifuged at $48,200 \mathrm{~g}$ for $30 \mathrm{~min}$ at $4^{\circ} \mathrm{C}$. The pellet was resuspended in $48 \mathrm{ml} 50 \mathrm{~mm} \mathrm{KPi}$ buffer, $\mathrm{pH} 7.0$, containing $10 \mathrm{~mm} \mathrm{MgSO}_{4}$. The sample was centrifuged at $750 \mathrm{~g}$ for $60 \mathrm{~min}$ at $4{ }^{\circ} \mathrm{C}$ and the yellowish, milky, supernatant fluid was carefully decanted and centrifuged at $48,200 \mathrm{~g}$ for $30 \mathrm{~min}$ at $4{ }^{\circ} \mathrm{C}$. The high speed pellet obtained as described above was resuspended by homogenization in $1 \mathrm{ml} 50 \mathrm{mM}$ KPi buffer (pH 7.0) containing $10 \%$ glycerol and frozen in small aliquots of $100 \mu \mathrm{l}$ and stored in liquid nitrogen.

The orientation of MsbA proteins in right-side-out membrane vesicles, inside-out membrane vesicles or proteoliposomes was assessed by determining the accessibility of the $\mathrm{N}$-terminal His-tag to digestion by protease $\mathrm{K}$ in the external buffer $^{41}$. Membrane proteins were diluted in $50 \mathrm{~mm}$ K-HEPES (pH 7.0) supplemented with $1 \mathrm{~mm} \mathrm{CaCl} 2$. The digestion was initiated by addition of proteinase $\mathrm{K}$ at an enzyme-membrane protein ratio of 1:25 (w/w). The samples were subsequently incubated at $0{ }^{\circ} \mathrm{C}$ for $10 \mathrm{~min}$. The reaction was terminated by the addition of $10 \mathrm{~mm}$ phenylmethanesulphonyl fluoride (from stock in ethanol), after which $3 \times$ SDS-PAGE sample-loading buffer and $1 \mathrm{~mm}$ DTT were added. The samples were incubated at RT for $10 \mathrm{~min}$ and analysed on immunoblot as described under 'Preparation of inside-out membrane vesicles'.

Cytotoxicity assays. L. lactis expressing MsbA-WT, MsbA-MD or MsbA- $\Delta$ K382, and non-expressing control cells were grown as described under 'Growth conditions and protein expression' at $30^{\circ} \mathrm{C}$ in 96 -well plates in the presence of a range of erythromycin concentrations. Nisin A was added at a concentration of $5 \mathrm{pg} \mathrm{ml}^{-1}$ to induce protein expression, and growth was monitored by measuring $\mathrm{OD}_{660}$ in a Versamax plate reader (Molecular Devices Wokingham, UK) at $30^{\circ} \mathrm{C}$. The maximum specific growth rate $\left(\mu_{\mathrm{m}}\right)$ was determined from the change in $\mathrm{OD}_{660}$ over time, by fitting the data to $N_{\mathrm{t}}=N_{0} \times e^{\mu_{\mathrm{m}} \times t}$ in which $N_{\mathrm{t}}$ and $N_{0}$ are the cell densities at times $t$ and $0 \mathrm{~h}$, respectively. The $\mu_{\mathrm{m}}$ of the cells grown in the absence of drug was set at $100 \%$ to calculate relative growth rates (Fig. $6 \mathrm{~g}$ ).

Statistical analyses. Significance of data obtained with whole cells and proteoliposomes was tested by one-way analysis of variance. Differences in proteinase- $\mathrm{K}$ and ATPase results were assessed using the unpaired student $-t$ test. Asterisks directly above bars in the histograms refer to comparisons with control; asterisks above lines refer to specific comparisons: ${ }^{\star} P<0.05$; ${ }^{*} P<0.01$; ${ }^{* * * P}<0.001 ;{ }^{* * *} P<0.0001$.

Data availability. Data that support the findings of this study have been deposited in the University of Cambridge data repository with the accession code 1810/255838 (https://www.repository.cam.ac.uk/handle/1810/255838) or available from the corresponding author upon reasonable request.

\section{References}

1. Du, D., van Veen, H. W., Murakami, S., Pos, K. M. \& Luisi, B. F. Structure, mechanism and cooperation of bacterial multidrug transporters. Curr. Opin. Struct. Biol. 33, 76-91 (2015)

2. Gottesman, M. M., Fojo, T. \& Bates, S. E. Multidrug resistance in cancer: role of ATP-dependent transporters. Nat. Rev. Cancer 2, 48-58 (2002).

3. Hardwick, L. J., Velamakanni, S. \& van Veen, H. W. The emerging pharmacotherapeutic significance of the breast cancer resistance protein (ABCG2). Br. J. Pharmacol. 151, 163-174 (2007).

4. Higgins, C. F. \& Gottesman, M. M. Is the multidrug transporter a flippase? Trends Biochem. Sci. 17, 18-21 (1992).

5. Bolhuis, H. et al. Multidrug resistance in Lactococcus lactis: evidence for ATP-dependent drug extrusion from the inner leaflet of the cytoplasmic membrane. EMBO J. 15, 4239-4245 (1996).

6. Borst, P. \& Elferink, R. O. Mammalian ABC transporters in health and disease. Annu. Rev. Biochem. 71, 537-592 (2002).

7. Reuter, G. et al. The ATP binding cassette multidrug transporter LmrA and lipid transporter MsbA have overlapping substrate specificities. J. Biol. Chem. 278, 35193-35198 (2003).

8. King, G. \& Sharom, F. J. Proteins that bind and move lipids: MsbA and NPC1 Crit. Rev. Biochem. Mol. Biol. 47, 75-95 (2012).

9. Rees, D. C., Johnson, E. \& Lewinson, O. ABC transporters: the power to change. Nat. Rev. Mol. Cell Biol. 10, 218-227 (2009).

10. Jones, P. M. \& George, A. M. A reciprocating twin-channel model for $\mathrm{ABC}$ transporters. Q. Rev. Biophys. 47, 189-220 (2014).

11. Hollenstein, K., Dawson, R. J. \& Locher, K. P. Structure and mechanism of ABC transporter proteins. Curr. Opin. Struct. Biol. 17, 412-418 (2007).

12. Ward, A., Reyes, C. L., Yu, J., Roth, C. B. \& Chang, G. Flexibility in the ABC transporter MsbA: alternating access with a twist. Proc. Natl Acad. Sci. USA 104, 19005-19010 (2007).

13. Gutmann, D. A., Ward, A., Urbatsch, I. L., Chang, G. \& van Veen, H. W. Understanding polyspecificity of multidrug $\mathrm{ABC}$ transporters: closing in on the gaps in ABCB1. Trends Biochem. Sci. 35, 36-42 (2010).

14. Doerrler, W. T., Gibbons, H. S. \& Raetz, C. R. MsbA-dependent translocation of lipids across the inner membrane of Escherichia coli. J. Biol. Chem. 279, 45102-45109 (2004). 
15. Woebking, B. et al. Drug-lipid A interactions on the Escherichia coli ABC transporter MsbA. J. Bacteriol. 187, 6363-6369 (2005).

16. Woebking, B. et al. Functional role of transmembrane helix 6 in drug binding and transport by the ABC transporter MsbA. Biochemistry 47, 10904-10914 (2008).

17. Eckford, P. D. \& Sharom, F. J. Functional characterization of Escherichia coli MsbA: interaction with nucleotides and substrates. J. Biol. Chem. 283, 12840-12850 (2008).

18. Zhou, Z., White, K. A., Polissi, A., Georgopoulos, C. \& Raetz, C. R. Function of Escherichia coli MsbA, an essential ABC family transporter, in lipid A and phospholipid biosynthesis. J. Biol. Chem. 273, 12466-12475 (1998).

19. Doerrler, W. T., Reedy, M. C. \& Raetz, C. R. An Escherichia coli mutant defective in lipid export. J. Biol. Chem. 276, 11461-11464 (2001).

20. Ghanei, H., Abeyrathne, P. D. \& Lam, J. S. Biochemical characterization of MsbA from Pseudomonas aeruginosa. J. Biol. Chem. 282, 26939-26947 (2007).

21. Balakrishnan, L., Venter, H., Shilling, R. A. \& van Veen, H. W. Reversible transport by the ATP-binding cassette multidrug export pump LmrA: ATP synthesis at the expense of downhill ethidium uptake. J. Biol. Chem. 279, 11273-11280 (2004).

22. Venter, H., Shilling, R. A., Velamakanni, S., Balakrishnan, L. \& Van Veen, H. W. An $\mathrm{ABC}$ transporter with a secondary-active multidrug translocator domain. Nature 426, 866-870 (2003).

23. Hellmich, U. A., Haase, W., Velamakanni, S., van Veen, H. W. \& Glaubitz, C. Caught in the act: ATP hydrolysis of an ABC-multidrug transporter followed by real-time magic angle spinning NMR. FEBS Lett. 582, 3557-3562 (2008).

24. van Veen, H. W., Margolles, A., Muller, M., Higgins, C. F. \& Konings, W. N. The homodimeric ATP-binding cassette transporter LmrA mediates multidrug transport by an alternating two-site (two-cylinder engine) mechanism. EMBO J. 19, 2503-2514 (2000).

25. Ishihama, Y. et al. Exponentially modified protein abundance index (emPAI) for estimation of absolute protein amount in proteomics by the number of sequenced peptides per protein. Mol. Cell Proteomics 4, 1265-1272 (2005).

26. Parveen, Z. et al. Molecular dissection of dual pseudosymmetric solute translocation pathways in human P-glycoprotein. Mol. Pharmacol. 79, 443-452 (2011).

27. Zolnerciks, J. K. et al. The Q loops of the human multidrug resistance transporter ABCB1 are necessary to couple drug binding to the ATP catalytic cycle. FASEB J. 28, 4335-4346 (2014).

28. Levy, D., Seigneuret, M., Bluzat, A. \& Rigaud, J. L. Evidence for proton countertransport by the sarcoplasmic reticulum Ca2( +)-ATPase during calcium transport in reconstituted proteoliposomes with low ionic permeability. J. Biol. Chem. 265, 19524-19534 (1990).

29. Lancaster, C. R. A P-type ion pump at work. Nat. Struct. Biol. 9, 643-645 (2002).

30. Smirnova, I., Kasho, V. \& Kaback, H. R. Lactose permease and the alternating access mechanism. Biochemistry 50, 9684-9693 (2011).

31. Eicher, T. et al. Coupling of remote alternating-access transport mechanisms for protons and substrates in the multidrug efflux pump AcrB. Elife 3, e02740 (2014).

32. Choudhury, H. G. et al. Structure of an antibacterial peptide ATP-binding cassette transporter in a novel outward occluded state. Proc. Natl Acad. Sci. USA 111, 9145-9150 (2014)

33. Dey, S. \& Rosen, B. P. Dual mode of energy coupling by the oxyanion-translocating ArsB protein. J. Bacteriol. 177, 385-389 (1995).

34. Kuroda, M., Dey, S., Sanders, O. I. \& Rosen, B. P. Alternate energy coupling of ArsB, the membrane subunit of the Ars anion-translocating ATPase. J. Biol. Chem. 272, 326-331 (1997).

35. Shilling, R. et al. A critical role of a carboxylate in proton conduction by the ATP-binding cassette multidrug transporter LmrA. FASEB J. 19, 1698-1700 (2005).

36. de Ruyter, P. G., Kuipers, O. P. \& de Vos, W. M. Controlled gene expression systems for Lactococcus lactis with the food-grade inducer nisin. Appl. Environ. Microbiol. 62, 3662-3667 (1996).
37. Venter, H., Velamakanni, S., Balakrishnan, L. \& van Veen, H. W. On the energy-dependence of Hoechst 33342 transport by the ABC transporter LmrA. Biochem. Pharmacol. 75, 866-874 (2008)

38. Margolles, A., Putman, M., van Veen, H. W. \& Konings, W. N. The purified and functionally reconstituted multidrug transporter LmrA of Lactococcus lactis mediates the transbilayer movement of specific fluorescent phospholipids. Biochemistry 38, 16298-16306 (1999).

39. Nicholls, D. G. \& Ferguson, S. J. Bioenergetics 4th edn (Academic Press, 2013).

40. Quintela, T. et al. Sex-related differences in rat choroid plexus and cerebrospinal fluid: a cDNA microarray and proteomic analysis. J. Neuroendocrinol. 28, http://dx.doi.org/10.1111/jne.12340 (2016).

41. Jin, Y., Nair, A. \& van Veen, H. W. Multidrug transport protein NorM from Vibrio cholerae simultaneously couples to sodium- and proton-motive force. J. Biol. Chem. 289, 14624-14632 (2014).

42. Doshi, R. et al. Molecular disruption of the power stroke in the ATP-binding cassette transport protein MsbA. J. Biol. Chem. 288, 6801-6813 (2013).

43. Otto, R., Lageveen, R. G., Veldkamp, H. \& Konings, W. N. Lactate efflux-induced electrical potential in membrane vesicles of Streptococcus cremoris. J. Bacteriol. 149, 733-738 (1982).

\section{Acknowledgements}

Himansha Singh is supported by the Cambridge Commonwealth, European and International Trust. Saroj Velamakanni was a recipient of a Cambridge Nehru Scholarship. Shen L. Wei was funded by the Cambridge Overseas Trust. This research in the Van Veen group was supported by Biotechnology and Biological Sciences Research Council (BBSRC) grant BB/I002383/1 and BB/C004663/1, Medical Research Council (MRC) grant G0401165 and by further support from the Human Frontier Science Program (HFSP) and the British Society for Antimicrobial Chemotherapy (BSAC).

\section{Author contributions}

H.S., S.V., M.J.D., J.H. and S.L.W. designed experiments, and generated and analysed data. H.S., S.V. and S.L.W. conducted reconstitution and transport experiments. M.J.D. and J.H. performed LC-MS/MS. H.W.v.V. conceptualized, guided and planned the project, experiments and analyses. H.W.v.V., H.S. and M.J.D. designed figures and wrote the paper with input from S.V. and S.L.W. All authors approved the final version of the manuscript.

\section{Additional information}

Supplementary Information accompanies this paper at http://www.nature.com/ naturecommunications

Competing financial interests: The authors declare no competing financial interests

Reprints and permission information is available online at http://npg.nature.com/ reprintsandpermissions/

How to cite this article: Singh, H. et al. ATP-dependent substrate transport by the ABC transporter MsbA is proton-coupled. Nat. Commun. 7:12387 doi: 10.1038/ncomms12387 (2016).

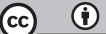

This work is licensed under a Creative Commons Attribution 4.0 International License. The images or other third party material in this article are included in the article's Creative Commons license, unless indicated otherwise in the credit line; if the material is not included under the Creative Commons license, users will need to obtain permission from the license holder to reproduce the material To view a copy of this license, visit http://creativecommons.org/licenses/by/4.0/

(C) The Author(s) 2016 